(C) 2018, THE AUTHORS. Published by FASS Inc. and Elsevier Inc. on behalf of the American Dairy Science Association ${ }^{\circledR}$. This is an open access article under the CC BY-NC-ND license (http://creativecommons.org/licenses/by-nc-nd/3.0/).

\title{
Pseudomonas fluorescens group bacterial strains are responsible for repeat and sporadic postpasteurization contamination and reduced fluid milk shelf life
}

\author{
S. J. Reichler, A. Trmčić, N. H. Martin, K. J. Boor, and M. Wiedmann ${ }^{1}$ \\ Milk Quality Improvement Program, Department of Food Science, Cornell University, Ithaca, NY 14853
}

\begin{abstract}
Postpasteurization contamination (PPC) of high temperature, short time-pasteurized fluid milk by gram-negative (GN) bacteria continues to be an issue for processors. To improve PPC control, a better understanding of PPC patterns in dairy processing facilities over time and across equipment is needed. We thus collected samples from 10 fluid milk processing facilities to (1) detect and characterize PPC patterns over time, (2) determine the efficacy of different media to detect PPC, and (3) characterize sensory defects associated with PPC. Specifically, we collected 280 samples of high temperature, short time-pasteurized milk representing different products (2\%, skim, and chocolate) and different fillers over 4 samplings performed over 11 mo at each of the 10 facilities. Standard plate count (SPC) as well as total GN, coliform, and Enterobacteriaceae $(\mathrm{EB})$ counts were performed upon receipt and after $7,10,14,17$, and $21 \mathrm{~d}$ of storage at $6^{\circ} \mathrm{C}$. We used $16 \mathrm{~S}$ rDNA sequencing to characterize representative bacterial isolates from (1) test days with SPC $>20,000$ $\mathrm{cfu} / \mathrm{mL}$ and (2) all samples with presumptive GN, coliforms, or EB. Day-21 samples were also evaluated by a trained defect judging panel. By d 21, 226 samples had $\mathrm{SPC}>20,000 \mathrm{cfu} / \mathrm{mL}$ on at least $1 \mathrm{~d}$ of shelf life; GN bacteria were found in 132 of these 226 samples, indicating PPC. Crystal violet tetrazolium agar detected PPC with the greatest sensitivity. Spoilage due to PPC was predominantly associated with Pseudomonas (isolated from 101 of the 132 samples with PPC); coliforms and EB were found in 27 and 37 samples with spoilage due to PPC, respectively. Detection of Pseudomonas and Acinetobacter was associated with lower flavor scores; coagulated, fruity fermented, and unclean defects were more prevalent in d-21 samples with PPC. Repeat isolation of Pseudomonas fluorescens
\end{abstract}

Received January 12, 2018.

Accepted May 11, 2018

${ }^{1}$ Corresponding author: mw16@cornell.edu group strains with identical partial 16S rDNA sequence types was observed in 8 facilities. In several facilities, specific lines, products, or processing days were linked to repeat product contamination with Pseudomonas with identical sequence types. Our data show that PPC due to Pseudomonas remains a major challenge for fluid milk processors; the inability of coliform and EB tests to detect Pseudomonas may contribute to this. Our data also provide important initial insights into PPC patterns (e.g., line-specific contamination), supporting the importance of molecular subtyping methods for identification of PPC sources.

Key words: postpasteurization contamination, Pseudomonas, shelf-life, spoilage, crystal violet tetrazolium agar

\section{INTRODUCTION}

Spoilage due to bacterial growth is a cause of consumer complaints and a contributor to dairy product waste, which claims an estimated $15 \%$ of production in the industrialized world at the consumer level (Gustavsson et al., 2011). Fluid milk spoilage specifically has been valued at $\$ 6.4$ billion per year in the United States (Buzby et al., 2014). Microbial spoilage is of particular concern and can be caused by either psychrotolerant sporeformers, which likely originate from raw milk, or by postpasteurization contamination (PPC). Whereas gram-positive (GP) bacteria can also recontaminate milk after pasteurization (Eneroth et al., 2001; Salustiano et al., 2009), bacteria responsible for PPC leading to fluid milk spoilage are typically gram-negative (GN) and are thought to originate from the processing environment (Schröder, 1984). Although several recent studies have explored the on-farm sources of psychrotolerant sporeformers (Miller et al., 2015a; Masiello et al., 2017), less information is available on sources of PPC in contemporary fluid milk processing facilities. Defects associated with GN-PPC include coagulation, bitter and astringent flavors (Bassette et al., 1986; Harwalkar et al., 1993), rotten, barny, cheesy, and fruity odors 
(Hayes et al., 2002), and pigment production (Seitz et al., 1961; Evanowski et al., 2017). Whereas the regulatory limit on bacterial counts in HTST-pasteurized fluid milk in the United States is $20,000 \mathrm{cfu} / \mathrm{mL}$, sensory defects due to GN-PPC typically require bacterial growth to $>5,000,000 \mathrm{cfu} / \mathrm{mL}$ (Punch et al., 1965), a level often reached during shelf life by milk with PPC (Martin et al., 2012).

Although most facilities perform microbial tests on HTST-pasteurized fluid milk, the methods most commonly used by industry either do not differentiate between GN bacteria and psychrotolerant sporeformers (e.g., SPC) or only detect a subset of GN bacteria responsible for PPC, such as coliforms and Enterobacteriaceae (EB). Whereas the Standard Methods for the Examination of Dairy Products (Frank and Yousef, 2004) specifies crystal violet tetrazolium agar (CVTA) for the enumeration of total GN bacteria, this method is not routinely used by dairy processing facilities, possibly because it uses a complex medium not available in ready-to-use form. However, CVTA has been well established as an effective medium for detection of GN bacteria (Randolph et al., 1973; Hervert et al., 2017), including Pseudomonas spp., which are a common cause of PPC, but are not detected with coliform and EB tests. After PPC detection, characterization and subtyping of isolates can provide important information on spoilage organism sources, transmission patterns, and persistence. Molecular subtyping methods have been used to identify sources of food-borne pathogens, but use of these tools for spoilage organisms is less common. Although many molecular methods are available, cost and ease of use are crucial factors. Hence, despite the availability of highly discriminatory subtyping tools, such as pulsed field gel electrophoresis (Nogarol et al., 2013) and whole genome sequencing (Andreani et al., 2015a), use of less discriminatory and cheaper methods (e.g., single-gene sequencing) can provide initial data that can be used to identify instances that may require follow-up with more expensive and discriminatory methods. Though practicality precludes the use of these methods for routine quality checks, they are valuable for troubleshooting when defect events occur and for understanding the mechanisms of product contamination and spoilage.

Though PPC is still commonly observed today (Martin et al., 2011a), little current information is available regarding the identity, prevalence, and quality effect of PPC bacteria from dairy processing facilities. Hence, the aim of our study was to use a longitudinal sampling approach and contemporary methods to characterize PPC and provide industry with data and tools needed to better control PPC.

\section{MATERIALS AND METHODS}

\section{Sample Collection and Handling}

Samples were collected from 10 dairy processing facilities producing packaged HTST-pasteurized fluid milk (see Table 1); facilities were located across the northeastern United States. For each facility, sample collections were performed on 4 separate occasions between July 2015 and May 2016. Samples of raw milk and finished product were either collected in-person by Milk Quality Improvement Program personnel or collected by facility personnel and delivered via overnight shipping. Samples collected at each collection date included (1) consumer packages representing HTSTpasteurized nonfat $(<0.2 \%$ milk fat $)$, reduced fat $(2 \%$ milk fat), and chocolate milk, as well as (2) a sample of raw milk from the silos used to produce the pasteurized products tested. Whenever possible, each of the pasteurized products was obtained from up to 3 different fillers per facility. This resulted in a diversity of packaging container volumes $[237 \mathrm{~mL}$ to $3.8 \mathrm{~L}$ (8 fluid ounces to 1 gallon)] and materials (high-density polyethylene, polyethylene terephthalate, and paperboard; Table 1). The number of pasteurized samples collected was between 3 and 9 per facility per sample collection, depending on the products manufactured and the number of fillers at each facility. Milk samples were transported to the Milk Quality Improvement Program laboratory in coolers packed with ice or ice packs, and were received at temperatures at or below $6^{\circ} \mathrm{C}$. Following receipt, samples were held at or below $4^{\circ} \mathrm{C}$ without freezing. Within $48 \mathrm{~h}$ of receipt, samples were divided into aliquots and stored at $6^{\circ} \mathrm{C}$ for shelf-life and sensory testing, as described by Martin et al. (2012).

\section{Microbiological Analysis of Raw Milk and Pasteurized Fluid Milk Samples}

Testing of raw milk was performed at the same time as initial testing for pasteurized products; tests performed included SPC and coliform count. Microbiological testing of pasteurized products took place on the initial day (the first day of testing, $0-5 \mathrm{~d}$ postprocessing) and 7, 10, 14, 17, and $21 \mathrm{~d}$ postprocessing; tests performed included SPC, coliform count, EB count, and total GN count. All tests were performed with 2 technical replicates per sample. The SPC was performed by spiral plating (Autoplate 4000, Advanced Instruments, Norwood, MA) onto standard methods agar (EMD Millipore Corporation, Billerica, MA) in accordance with Standard Methods for the Examination of Dairy Products (Laird et al., 2004). Coliform and EB counts 
Table 1. Characteristics of the 10 HTST-pasteurized fluid milk processing facilities in the northeastern United States from which consumer packages of pasteurized fluid milk were collected on 4 occasions between July 2015 and May 2016

\begin{tabular}{lccc}
\hline Facility & $\begin{array}{c}\text { Total annual volume } \\
(\text { million L) }\end{array}$ & Number of fillers & Number of employees \\
\hline A & $>100$ & 6 & $>200$ \\
B & $11-100$ & 2 & $51-100$ \\
C & $>100$ & 7 & $101-150$ \\
D & $>100$ & 10 & $151-200$ \\
E & $11-100$ & 6 & $151-200$ \\
F & $>10$ & 2 & $<50$ \\
G & $>100$ & 4 & $51-100$ \\
H & 100 & 4 & $151-200$ \\
I & $11-100$ & 4 & $51-100$ \\
J & $11-100$ & 6 & $>200$ \\
\hline
\end{tabular}

were performed using 3M Coliform Count Petrifilms and EB count Petrifilms, respectively (3M Food Safety, St. Paul, MN), in accordance with Standard Methods for the Examination of Dairy Products (Davidson et al., 2004). Total GN count was performed in accordance with Standard Methods for the Examination of Dairy Products (Frank and Yousef, 2004) with the following modification: $50 \mu \mathrm{L}$ of the sample or an appropriate dilution of the sample was spiral plated onto CVTA.

\section{Sensory Defect Panel Training and Evaluation of Samples}

Defect panelist candidates were recruited from Cornell University students and staff and prescreened for sensory acuity using common odors and tastes. Briefly, candidates who passed prescreening were trained to recognize the defects described in Table 2 . To be eligible for the panel, candidates had to complete a lecture- based training and twelve 30-min practice evaluation sessions using simulated defective samples of $2 \%$ and skim HTST milk. These sessions were followed by two 30-min final evaluations to determine training efficacy; only candidates who correctly identified $\geq 70 \%$ of samples in the final evaluations were eligible for inclusion on the panel.

Defect judging was performed for each sample on d 21 of shelf life, as previously described (Martin et al., 2012). Briefly, samples were warmed to approximately $15^{\circ} \mathrm{C}$ and each sample was evaluated by 6 panel members, selected from the pool of eligible candidates. Panel members noted defects and assigned an overall flavor score for every sample evaluated. Specific defects were reported if they were noted by 2 or more panelists. Overall flavor score and defect judging data were collected from the panelists using either Compusense Cloud (Compusense Inc., Guelph, ON, Canada) or RedJade (Tragon Corp., Redwood Shores, CA) platforms

Table 2. Sensory defects included in panelist training, their typical sources, and the methods by which panelists were trained to recognize the defects

\begin{tabular}{lll}
\hline Defect & Typical source & Training method \\
\hline Acid & Microbial & Simulated milk sample \\
Astringent & Microbial & Description in lecture \\
"Band-Aid" & Microbial & Description in lecture \\
Bitter & Microbial & Simulated milk sample \\
Coagulated & Microbial & Description in lecture \\
Cooked & Processing & Simulated milk sample \\
Cowy/barny & Farm & Description in lecture \\
Feed & Farm & Simulated milk sample \\
Flat & Processing & Simulated milk sample \\
Foreign/chemical & Farm/processing/storage & Description in lecture \\
Fruity/fermented & Microbial & Simulated milk sample \\
Lacks freshness & Microbial/storage & Description in lecture \\
Light oxidized & Storage/handling & Simulated milk sample \\
Lipid oxidized & Processing/storage & Description in lecture \\
Malty & Microbial & Simulated milk sample \\
Milk carton & Packaging & Simulated milk sample \\
Rancid & Microbial & Simulated milk sample \\
Unclean & Microbial & Description in lecture \\
\hline
\end{tabular}


running as web-based applications on tablet computers. The information requested from the panelists was identical across both platforms.

\section{Bacterial Isolation and Preservation}

For samples with $\mathrm{SPC}>20,000 \mathrm{cfu} / \mathrm{mL}, 1$ colony representing each visually unique colony morphology on SPC medium (standard methods agar) was selected for further characterization and biobanking. For samples that displayed characteristic colonies on Coliform Count Petrifilms, EB, or CVTA medium, 1 colony was selected from each technical replicate for a given medium; if multiple morphologies were observed within or across technical replicates, 1 colony representing each visually unique colony morphology was selected. Selected colonies were subcultured at $32^{\circ} \mathrm{C}$ for $48 \mathrm{~h}$ on brain heart infusion (BHI) agar (BD Diagnostics, Sparks, MD), evaluated for purity, and subsequently grown at $32^{\circ} \mathrm{C}$ in BHI broth for 18 to $24 \mathrm{~h}$ (BD Diagnostics) before being frozen at $-80^{\circ} \mathrm{C}$ in with the addition of $15 \%$ glycerol. Detailed information on the origin of all bacterial isolates was deposited in Food Microbe Tracker (http:// www.foodmicrobetracker.com; Vangay et al., 2013).

\section{S rDNA and rpoB Sequencing}

Isolates were recovered from frozen stock onto BHI agar plates, which were incubated for 18 to $24 \mathrm{~h}$ at $32^{\circ} \mathrm{C}$. Whole-cell lysates were prepared by inoculating $100 \mu \mathrm{L}$ of sterile water with a single colony obtained from the BHI plates; this suspension was subsequently heated to $95^{\circ} \mathrm{C}$ for $15 \mathrm{~min}$, followed by cooling to $4^{\circ} \mathrm{C}$ and clearing by centrifugation $\left(2,916 \times g, 3 \mathrm{~min}, 4^{\circ} \mathrm{C}\right)$. A $2-\mu \mathrm{L}$ volume of the supernatant was used for PCR. Briefly, an internal fragment of approximately $765 \mathrm{bp}$ of the $16 \mathrm{~s}$ rDNA gene for each isolate was amplified using GoTaq Flexi chemistry (Promega, Fitchburg,
WI) and primers PEU7 (Rothman et al., 2002) and DG74 (Greisen et al., 1994; Table 3). Following reaction cleanup with exonuclease I and shrimp alkaline phosphatase (Affymetrix Inc., Santa Clara, CA; Werle et al., 1994), the PCR product was directly sequenced using BigDye 3.1 cycle sequencing chemistry (Thermo Fisher, Waltham, MA) and primers PEU7 and DG74. Postreaction cleanup and capillary gel electrophoresis were performed by the Biotechnology Resource Center (Cornell University, Ithaca, NY) using Optima DTR 96-well plate columns (Edge BioSystems, Gaithersburg, MD) per manufacturer instructions (https://www .edgebio.com/protocols) and an ABI 3730xl capillary DNA Analyzer (Thermo Fisher). Sequencing of rpoB was performed for isolates presumed to represent GP bacteria, based on the spoilage pattern of the sample from which they originated (no positive results on selective media for GN bacteria). The $r p o B$ PCR was performed as previously described using GoTaq Green chemistry (Promega) and primers RZrpoBFV2 and RZrpoBRV2 or RZrpoBFV3 and RZrpoBRV3 (Miller et al., 2015b; Table 3). Sequencing proceeded as described for $16 \mathrm{~S}$ rDNA PCR products using the rpoB primers in place of the $16 \mathrm{~S}$ primers. For isolates that did not yield data upon initial sequencing, sequencing was repeated only if the identity of the isolates were required to confirm or deny the presence of PPC in the sample from which they originated. Detailed internally developed standard operating procedures describing the $16 \mathrm{~S}$ and rpo $B \mathrm{PCR}$ and sequencing can be accessed online (https://cornell.box.com/v/Reichler2018). Among the 2,447 isolates collected, DNA sequence data were obtained for 1,919 (1,506 16S rDNA, 413 rpoB).

\section{S rDNA Sequence Analysis and Sequence Typing}

Initial analysis of sequences (trimming ends, resolution of ambiguities, and generation of a consensus

Table 3. The DNA sequences of the primers used for PCR amplification and sequencing of bacterial isolates obtained from samples of HTSTpasteurized fluid milk over shelf-life

\begin{tabular}{|c|c|c|c|}
\hline Primer name & Primer description & Primer use $^{1}$ & Primer sequence $\left(5^{\prime} \rightarrow 3^{\prime}\right)^{2}$ \\
\hline 16S-DG74 & $\begin{array}{l}\text { Reverse primer for internal segment of } 16 \mathrm{~S} \\
\text { rRNA gene }\end{array}$ & Presumptive gram-negative & AGGAGGTGATCCAACCGCA \\
\hline $\mathrm{RZrpoBFV} 2^{3}$ & Forward primer for $r p o B$, version 2 & Presumptive gram-positive & AARYTNGGHCCTGAAGAAAT \\
\hline RZrpoBRV2 ${ }^{3}$ & Reverse primer for $r p o B$, version 2 & Presumptive gram-positive & TGNARYTTRTCATCAACCATGTG \\
\hline $\mathrm{RZ}_{\text {rpoB }} \mathrm{FV} 3^{3}$ & Forward primer for $r p o B$, version 3 & Presumptive gram-positive & AARYTNGGHCCDGARGAAAT \\
\hline
\end{tabular}


sequence) was performed using SeqTrace (Stucky, 2012) or Sequencher (Gene Codes Corporation, Ann Arbor, MI). Organism genus and species assignments were obtained by a local implementation of BLAST using the Ribosomal Database Project database (Cole et al., 2009; Priyam et al., 2015). Sequence typing was performed for all sequenced GN isolates; the consensus sequences for all organisms identified as GN were aligned and trimmed to an approximately 552-nucleotide region (actual region length ranged from 528 to 553 nucleotides, though 552 was typical) using Aliview (Larsson, 2014). Isolates were assigned a different sequence type (ST) if they differed by $\geq 1$ nucleotide over the aligned region. An internally developed Python script was used to document and remove duplicate sequences (see Supplemental Material S1; https://doi .org/10.3168/jds.2018-14438). To check for errors, the sequences representing presumptive unique ST were searched against themselves using BLAST. For every pair of presumptively unique sequences with 5 or fewer nucleotide differences between them, comparisons of the original chromatograms were performed in Sequencher at all positions of disagreement. The resulting type sequences were used to assign $16 \mathrm{~S}$ rDNA ST to all isolates.

\section{rpoB Sequence Analysis and Allelic Typing}

The $r p o B$ sequence analysis was performed essentially as described in the previous subsection for $16 \mathrm{~S}$ rDNA sequence analysis. Isolate genus and species identifications and the assignment of pre-existing rро $B$ allelic types were performed by running BLAST queries of the sequences against our internal rpoB allelic type database (Ivy et al., 2012; Priyam et al., 2015). Assignment of novel allelic types was performed as previously described, using Aliview in place of BioEdit (Ivy et al., 2012; Larsson, 2014).

\section{Phylogenetic Analysis}

A maximum likelihood tree representing all $16 \mathrm{~S}$ rDNA ST was constructed by aligning the sequences using MUSCLE followed by a maximum likelihood analysis (Kimura 2-parameter model, gamma-distributed rates among sites) performed using MEGA6 (Tamura et al., 2013). The resulting tree was visualized using FigTree (v. 1.4.2; http://tree.bio.ed.ac.uk/software/figtree/).

\section{Data Curation and Statistical Analysis}

All testing and characterization data were stored in a relational database (Access 2016; Microsoft Corp., Redmond, WA). Statistical analyses were performed in R base package (version 3.3.3; R Foundation for Statistical Computing, Vienna, Austria). The figure summarizing the incidence of spoilage due to PPC at each processing facility and Supplemental Figure S1 (https://doi.org/10 $.3168 /$ jds.2018-14438) were generated using the ggplot2 package (Wickham, 2016). To compare rates of PPC between facilities, least squares means were calculated from a mixed effects logistic regression using the dplyr, lme4, and lsmeans packages (Bates et al., 2015; Lenth, 2016; Wickham et al., 2017). The mixed effect linear model used to assess flavor scores among samples with different contamination patterns was created using the lmerTest package (Kuznetsova et al., 2017).

\section{RESULTS}

\section{Identification of Spoilage due to PPC over Shelf Life}

Among 280 HTST fluid milk samples collected from 10 processing facilities over 4 sample collections at each facility, 226 samples (81\%) showed bacterial counts above the quality threshold (QT) over shelf life, defined as a bacterial count of $>20,000 \mathrm{cfu} / \mathrm{mL}$ for at least 1 of the 6 test days (initial, 7, 10, 14, 17, and 21; Supplemental Figure S1, https://doi.org/10.3168/ jds.2018-14438). This cutoff was selected as the US Pasteurized Milk Ordinance specifies an upper limit of $20,000 \mathrm{cfu} / \mathrm{mL}$ for pasteurized fluid milk (FDA, 2015). However, we acknowledge that actual spoilage due to bacteria-induced defects detectable by humans typically requires bacterial populations that are considerably higher than this cutoff; previous studies reported that counts exceeding $5,000,000 \mathrm{cfu} / \mathrm{mL}$ are needed to yield detectable defects (Punch et al., 1965). The 54 samples that did not exceed the QT at any test day showed a geometric mean bacterial count of $784 \mathrm{cfu} / \mathrm{mL}$ at d 21 as compared with a geometric mean bacterial count of $5,260,000 \mathrm{cfu} / \mathrm{mL}$ at $\mathrm{d} 21$ for the samples that did exceed the QT (Supplemental Figure S2; https://doi .org/10.3168/jds.2018-14438). By milk type, $69 \%$ of the skim milk samples $(72 / 105), 80 \%$ of the $2 \%$ milk samples $(83 / 104)$, and $100 \%$ of the chocolate milk samples (71/71) exceeded the QT over shelf life (Supplemental Figure S1; https://doi.org/10.3168/jds.2018-14438).

A mean of 8.5 isolates were characterized per sample that exceeded the QT over shelf life. Whereas detailed characterization results are described in a subsequent section, these data also allowed us to determine whether samples with counts above the QT were characterized by the presence of GN or GP organisms. Among the 226 samples that exceeded the QT over shelf life, $58 \%$ $(\mathrm{n}=132)$ yielded GN bacterial isolates, including 72 samples where all isolates characterized were identified as GN genera and 60 samples where, in addition to GN 
Table 4. Bacterial genera present in the 226 samples of HTST-pasteurized milk samples that reached the quality threshold ( $>20,000 \mathrm{cfu} / \mathrm{mL})$ at any point over $21 \mathrm{~d}$ of refrigerated shelf-life

\begin{tabular}{|c|c|c|c|c|c|c|}
\hline Genus $^{1}$ & $\begin{array}{l}\text { Samples with } \\
\text { S-PPC }^{2}\end{array}$ & $\begin{array}{l}\text { Samples without } \\
\text { S-PPC }\end{array}$ & \multicolumn{4}{|c|}{ Genera traits } \\
\hline Paenibacillus & 49 & 89 & + & - & - & + \\
\hline Bacillus & 19 & 49 & + & - & - & + \\
\hline Acinetobacter & 17 & 0 & - & - & - & - \\
\hline Stenotrophomonas & 11 & 0 & - & - & - & - \\
\hline Lelliottia & 7 & 0 & - & $+1-$ & + & - \\
\hline Raoultella & 6 & 0 & - & $+1-$ & + & - \\
\hline Citrobacter & 6 & 0 & - & + & + & - \\
\hline Viridibacillus & 5 & 5 & + & - & - & + \\
\hline Janthinobacterium & 5 & 0 & - & - & - & - \\
\hline Hafnia & 5 & 0 & - & + & + & - \\
\hline Lactococcus & 4 & 2 & + & - & - & - \\
\hline Psychrobacter & 3 & 0 & - & - & - & - \\
\hline Serratia & 3 & 0 & - & $+/-$ & + & - \\
\hline Limnohabitans & 3 & 0 & - & - & - & - \\
\hline Enterobacter & 3 & 0 & - & + & + & - \\
\hline Enterococcus & 2 & 6 & + & - & - & - \\
\hline Leuconostoc & 1 & 4 & + & - & - & - \\
\hline Staphylococcus & 0 & 8 & + & - & - & - \\
\hline Solibacillus & 0 & 3 & + & - & - & + \\
\hline Microbacterium & 0 & 3 & + & - & - & - \\
\hline $\operatorname{Rare}^{5}$ & 23 & 5 & $+1-$ & $+/-$ & $+/-$ & $+/-$ \\
\hline
\end{tabular}

${ }^{1}$ Genus classification was determined by sequencing $16 \mathrm{~S}$ rDNA or rpoB.

${ }^{2}$ Spoilage due to postpasteurization contamination: sample SPC of $>20,000 \mathrm{cfu} / \mathrm{mL}$ on 1 or more day of testing over $21 \mathrm{~d}$ of shelf-life at $6^{\circ} \mathrm{C}$, and DNA sequencing-confirmed isolation of gram-negative bacterial genera from the sample.

${ }^{3}+/$ - indicates that some members of this genus meet the criteria for inclusion as coliforms (i.e., produces gas and acid within $48 \mathrm{~h}$ at $32-35^{\circ} \mathrm{C}$ ), but all may not (Imhoff, 2005).

${ }^{4}$ Enterobacteriaceae.

${ }^{5} 20$ additional bacterial genera that were present in either 1 or 2 samples each.

isolates, at least $1 \mathrm{GP}$ isolate was identified. Consistent with previous studies (Thomas and Druce, 1969), we defined PPC as the presence of DNA sequencingconfirmed GN genera in pasteurized finished product. However, it is possible that high levels of GN bacteria in raw milk could yield pasteurization survivors that would spoil finished product (Macaulay et al., 1963; Dabbah et al., 1971; Weckbach and Langlois, 1977). However, in the United States, regulations require $<300,000 \mathrm{cfu} / \mathrm{mL}$ for commingled grade A raw milk (FDA, 2015), and the geometric mean SPC for raw milk in this study was $26,200 \mathrm{cfu} / \mathrm{mL}(4.4 \mathrm{log})$. This suggests that the presence of GN bacteria in our study was most likely due to PPC (even though 3/38 raw milk samples did exceed $300,000 \mathrm{cfu} / \mathrm{mL}$ ). Consequently, we classified all 132 milk samples that exceeded the QT over $21 \mathrm{~d}$ of shelf life and yielded 1 or more isolates from GN genera as showing evidence of spoilage due to PPC
(S-PPC). Among the 132 samples with evidence of SPPC, $101(77 \%)$ yielded at least $1 \mathrm{GN}$ isolate identified as Pseudomonas. Among the 94 samples that exceeded the QT over $21 \mathrm{~d}$ but did not yield any GN bacteria, 89 and 49 samples yielded at least 1 isolate representing the genera Paenibacillus or Bacillus, respectively; in 44 of these samples we identified both Paenibacillus and Bacillus (Table 4).

Samples that exceed the QT and either (1) yielded GN bacteria (S-PPC), with or without concomitant isolation of GP bacteria, or (2) only yielded GP bacteria also showed distinct patterns of total bacterial numbers over $21 \mathrm{~d}$ of incubation at $6^{\circ} \mathrm{C}$ (Supplemental Figure S2; https://doi.org/10.3168/jds.2018-14438). For d 7 through 21, median bacterial counts were always higher for samples with GN bacteria as compared with samples that only yielded GP bacteria. For example, at d 10 of shelf life, the median SPC for samples with GN 
bacteria was approximately 20,000 $\mathrm{cfu} / \mathrm{mL}$, whereas the median SPC for samples which only yielded GP bacteria was below $1,000 \mathrm{cfu} / \mathrm{mL}$.

Among the 54 samples with bacterial counts below the QT over shelf life, 3 samples yielded positive results on media designed to detect GN bacteria (i.e., CVTA, coliform Petrifilm, EB Petrifilm). All 3 of these samples were positive on CVTA, and isolates obtained from these samples were identified as belonging to GN genera (Pseudomonas from 2 samples and Acinetobacter from 1 sample). These samples were considered to show evidence for PPC, but not as S-PPC due to the bacterial counts consistently below the QT over shelf life.

\section{Bacterial Genera Responsible for Spoilage over Shelf Life}

To further characterize spoilage patterns, $16 \mathrm{~S}$ rDNA sequence data were obtained for 1,322 GN isolates. The $16 \mathrm{~S}$ rDNA data classified isolates into 10 taxonomic classes within the Alpha-, Beta-, and Gammaproteobacteria, and 1 class within the Flavobacteria (Supplemental Figure S3; https://doi.org/10.3168/jds.2018-14438). Gammaproteobacteria, which includes Pseudomonas and Enterobacteriaceae, were most heavily represented. The 874 Pseudomonas isolates characterized from the 101 S-PPC samples (Table 4) represented 55 unique ST. All other GN genera were found in 20 or fewer samples; additional GN genera found in samples included Acinetobacter (17 samples, 53 isolates, 4 ST) and Stenotrophomonas (11 samples, 29 isolates, $1 \mathrm{ST}$ ).

To characterize the spoilage patterns of milk with counts above the QT from which no presumptive GN bacteria were isolated, rро $B$ sequence data were collected for 411 GP isolates. In addition, 185 isolates for which $16 \mathrm{~S}$ rDNA sequence data were obtained were identified as GP based on the sequence data. Combined, these data provided characterization of 596 GP bacteria. These data showed that among all 226 samples that exceeded the QT over shelf life, 138 samples yielded at least 1 Paenibacillus isolate, and 68 yielded at least 1 Bacillus isolate; several of these represent samples that also yielded GN bacteria and, hence, were considered spoiled due to PPC despite the concomitant isolation of GP bacteria. All other GP genera were isolated from 20 or fewer samples; additional GP genera found in samples included Psychrobacillus (18 samples) and Viridibacillus (10 samples; Table 4).

\section{Detection of Coliforms and Enterobacteriaceae}

Among the 280 samples, 27 (10\%) were culturepositive for coliforms (Supplemental Table S1; https:// doi.org/10.3168/jds.2018-14438) and 38 (14\%) were culture positive for EB over shelf life (meaning at least 1 testing day yielded positive results for these organisms). By comparison, non-EB non-coliform GN genera were isolated from 129 samples (46\%), and Pseudomonas specifically was isolated from 103 samples (37\%; 101 above the QT and 2 below the QT). Whereas 23 coliform positive samples were also positive for EB, 4 samples were coliform-positive, EB-negative. Three of the 4 samples that were positive for coliforms and negative for EB had coliform counts of $1 \mathrm{cfu} / \mathrm{mL}$; hence it is likely that they tested negative for EB because the organism concentration was near the limit of detection. Isolates from 2 of these samples were identified as Rahnella and Citrobacter, while the isolate from the third sample did not produce $16 \mathrm{~S}$ rDNA sequence data. Raoultella was identified from the fourth sample that was positive for coliforms $\left(>1.5 \times 10^{2} \mathrm{cfu} / \mathrm{mL}\right.$, which is too numerous to count), suggesting a false negative for EB as Raoultella is expected to grow on EB Petrifilms (Hervert et al., 2016).

\section{Ability of Different Microbiological Tests to Detect PPC over Shelf Life}

Data for the 280 HTST milk samples tested were also used to assess the ability of CVTA, coliform, and EB tests to detect S-PPC (Table 5). A sample was classified as positive for GN (CVTA), coliforms (coliform Petrifilm), or EB (EB Petrifilm) if a sample was positive on the given medium on at least 1 test day. Coliform, EB, and CVTA tests were positive for 27, 36 , and 131 of the 132 samples classified as showing SPPC, respectively. The CVTA produced a positive result for all 131 samples that yielded sequence-confirmed Proteobacteria, a major GN phylum (131/131; Table 5 and Supplemental Figure S3, https://doi.org/10.3168/ jds.2018-14438), but produced a negative result for the 1 sample that contained a sequence-confirmed Bacteroidetes, another GN phylum (Table 5 and Supplemental Figure S3). Among the 148 samples that showed no evidence for S-PPC, 0, 2, and 21 tested positive on coliform Petrifilm, EB Petrifilm, and CVTA, respectively. For the 21 samples with no evidence of S-PPC that yielded positive results on CVTA (Table 5), sequencing of 43 isolates collected from positive CVTA plates predominantly classified isolates into GP genera, including Paenibacillus (31), Bacillus (4), Lactococcus (2), and Enterococcus (2), but also identified some isolates classified into the GN genera Pseudomonas (3) and Acinetobacter (1). Although Pseudomonas and Acinetobacter are typically associated with S-PPC, our results do not indicate false-positive results for CVTA, 
Table 5. Performance of culture-based methods for detection of spoilage due to postpasteurization contamination (S-PPC) compared with 16S rDNA sequencing in 280 samples of pasteurized milk over $21 \mathrm{~d}$ of refrigerated shelf-life

\begin{tabular}{|c|c|c|c|c|c|c|c|c|}
\hline Technique $^{1}$ & $\begin{array}{c}\text { Days of } \\
\text { shelf-life }^{2}\end{array}$ & $\begin{array}{c}\text { Positive } \\
\text { when S-PPC } \\
\text { present }\end{array}$ & $\begin{array}{c}\text { Percent } \\
\text { sensitivity } \\
\text { for S-PPC }\end{array}$ & $\begin{array}{c}\text { Positive } \\
\text { when S-PPC } \\
\text { absent }\end{array}$ & $\begin{array}{c}\text { Negative } \\
\text { when S-PPC } \\
\text { present }\end{array}$ & $\begin{array}{c}\text { Negative } \\
\text { when S-PPC } \\
\text { absent }\end{array}$ & $\begin{array}{c}\text { Percent } \\
\text { specificity } \\
\text { for S-PPC }\end{array}$ & Total \\
\hline CVTA & All & 131 & 99.2 & 21 & 1 & 127 & 85.8 & 280 \\
\hline $\mathrm{EB}$ & All & 36 & 27.3 & 2 & 96 & 146 & 98.6 & 280 \\
\hline $\mathrm{SPC}>20,000$ & 7 & 31 & 23.5 & 0 & 101 & 148 & 100.0 & 280 \\
\hline $\mathrm{SPC}>20,000$ & 10 & 65 & 49.2 & 4 & 67 & 144 & 97.3 & 280 \\
\hline
\end{tabular}

\footnotetext{
${ }^{1}$ Techniques: CVTA $=$ crystal violet tetrazolium agar; $\mathrm{CC}=$ Coliform Count Petrifilm (3M Food Safety, St. Paul, MN); EB = Enterobacteriaceae Petrifilm (3M); SPC >20,000 = standard plate count greater than 20,000 $\mathrm{cfu} / \mathrm{mL}$ (above the quality threshold).

${ }^{2}$ Samples were plated on d 7, 10, 14, 17, and 21 postprocessing. All indicates that results from all days of plating were included (i.e., for CVTA, a positive on any day was considered a positive result for that sample).

${ }^{3}$ Sensitivity $=$ number of samples positive when spoilage due to PPC present out of 132 samples with spoilage due to PPC.

${ }^{4}$ Specificity $=$ number of samples negative when spoilage due to PPC absent out of 148 samples without spoilage due to PPC.

${ }^{5} 23 / 27$ also positive for EB.
}

but rather suggest that some GN isolates present in milk may not grow to above $20,000 \mathrm{cfu} / \mathrm{mL}$ over $21 \mathrm{~d}$ of storage at $6^{\circ} \mathrm{C}$. These data, however, suggest that plating of milk samples on CVTA with qualitative scoring of results (i.e., CVTA positive or negative) does yield false-positive results for detection of samples with S-PPC. Overall, qualitative identification of samples as positive on coliform Petrifilm, EB Petrifilm, and CVTA (on any day of shelf life) had sensitives of 21, 27, and $99 \%$ and specificities of 100,99 , and $86 \%$ for detection of milk samples with S-PPC, respectively (Table 5). Low sensitivities for coliform and EB Petrifilm do not suggest low sensitivity with regard to their ability to detect their target organisms, but low sensitivity for detection of milk samples that show S-PPC.

As SPC test results for samples earlier in shelf life may also be used to identify samples with PPC, we also examined whether SPC values above the QT obtained from early or mid shelf life samples (d 7, 10, and 14) could be used identify samples that would show S-PPC (Table 5). Among the 132 samples that showed S-PPC, 31, 65, and 95 showed SPC above the QT at d 7, 10, and 14 , which translates to 23,49 , and $72 \%$ sensitivity, respectively (Table 5). Specificity for detection of S-PPC from d 7, 10, and 14 SPC values above the QT were 100,97 , and $80 \%$, respectively.

\section{Effect of PPC and Sporeformers on Sensory Quality and Defect Prevalence}

Association of flavor scores with the detection of specific bacterial genera was complicated by the isolation of multiple genera from 72 of 280 samples on d 21 of shelf life (i.e., the day when overall flavor scores were determined). To assess the contribution of differ- ent bacterial genera to low sensory scores, we designed a mixed effect linear regression model that predicted overall flavor score from the explanatory variables of (1) the d-21 SPC value, (2) the individual presence or absence of the 6 genera that were isolated from 5 or more samples on d 21 of shelf life (i.e., Paenibacillus, Pseudomonas, Bacillus, Stenotrophomonas, Enterococcus, and Acinetobacter), and (3) the presence or absence of any bacterial genus within EB (e.g., Pantoea, Citrobacter). Dairy processing facility, sample collection date, panelist identification, and sample identification were included as random effects (Table 6). Significant negative effects on the flavor score, indicating a sample judged less favorably by the panel due to the presence of defects, were identified for SPC value $(P<0.001)$, the presence of Pseudomonas $(P<0.001)$, and the presence of Acinetobacter $(P=0.04)$. Presence of any genus from the EB had a marginally significant negative effect on sensory score $(P=0.05)$. Presence of Pseudomonas had the largest effect size $(-3.18)$, followed by Acinetobacter (-1.53) and EB (-0.91). Presence of Paenibacillus, on the other hand, showed a small but significant positive effect on the sensory score $(P=0.02)$. This indicates that, assuming equal SPC, milk contaminated with Paenibacillus had higher sensory scores than milk contaminated with other spoilage organisms.

We also examined the prevalence of specific sensory defects, identified on d 21 of shelf life by the defect panel, in (1) samples that showed S-PPC specifically on d 21 (d-21 SPC above the QT and sequencingconfirmed presence of GN genera) and (2) samples with SPC above the QT that lacked evidence of GN contamination (Figure 1). No defect judging data were available for 4 of the 280 samples collected. Among the 276 samples for which defect judging was performed, 
210 showed d-21 SPC above the QT. Whereas 132 samples showed evidence of S-PPC at any of the test days (which is the number discussed in preceding sections), only 77 samples showed evidence of S-PPC specifically at $\mathrm{d} 21$. This was likely caused by some samples that originally had very low levels of GN bacteria such that the bacteria were only portioned into and ultimately spoiled some, but not all, tested aliquots (e.g., d-14 or -17 aliquot, but not d-21 aliquot).

Significance of differences in defect prevalence were determined in $\mathrm{R}$ using Fisher's exact tests, with $P$ values corrected for multiple comparisons using the Holm method. Coagulation occurred in $44 \%$ of samples with evidence of S-PPC at d 21 (34 of 77), and in $<1 \%$ of samples without S-PPC at d 21 (1 of 134; $P$ $<0.001)$. Fruity fermented and unclean defects were also more prevalent in samples with S-PPC at d 21 (found in 14 and 15 of the 74 samples, respectively) as compared with samples without S-PPC at d 21 (7 and 7 of 134; $P<0.1$ and $P<0.05)$. Whereas 54 of the 134 samples (40\%) with no evidence of S-PPC at d 21 were described by the panel as lacking in freshness, only 12 of 77 ( $16 \%$ of) samples with evidence of S-PPC at d 21 were described as lacking freshness $(P<0.05)$. Not clearly defined, meaning that multiple panelists recorded defects but no consensus was reached among them, was also more prevalent in samples with no evidence of S-PPC at d 21 (36 of 134; 26\%) as compared with samples with evidence of S-PPC at d 21 ( 5 of 77 or $6 \% ; P<0.05)$. The "Band-Aid" defect was present exclusively in chocolate milk samples: 13 of 26 chocolate milk samples with and 13 of 45 chocolate milk samples without evidence of S-PPC at d 21 showed this defect (no significant difference).

\section{Analysis of GN Spoilage Frequency by Facility}

Among the 10 facilities included in our study, the proportion of samples with evidence of S-PPC at any test day ranged from 13 to $74 \%$ among all samples collected across all 4 sample collections (Figure 2). Facility B showed the lowest prevalence of S-PPC, at $13 \%$ of samples $(2 / 15)$. Facility D had the highest prevalence of samples with S-PPC at $74 \%(25 / 34)$. To determine if the levels of S-PPC differed between facilities, we fitted a mixed effects logistic regression with sampling date as a random effect, processing facility as a fixed effect, and S-PPC level as the response. Pairwise differences in means were estimated and significance was reported with false discovery rate multiple testing correction. Facilities B and D had levels of S-PPC that were significantly different from each other, whereas no significant differences existed among the remaining 8 facilities. In some facilities the proportion of samples with evidence of S-PPC also varied considerably between the 4 sample collections. For example, the incidence of S-PPC was very consistent over the 4 samplings for facilities $\mathrm{A}$ and $\mathrm{C}$, with standard deviations of 7 and $3 \%$, respectively. On the other hand, the incidence of S-PPC varied considerably between sampling for facilities F, G, and I, with standard deviations of 36, 28, and $19 \%$, respectively.

Table 6. Associations between the presence of commonly isolated bacterial genera and the d-21 overall flavor score of HTST-pasteurized milk samples collected from 10 northeastern United States dairy processing facilities over 11 mo $(\mathrm{n}=276)^{1}$

\begin{tabular}{lccrrr}
\hline Variable & Estimate $^{2}$ & SE $^{3}$ & df $^{4}$ & t-statistic $^{5}$ & $P$-value \\
\hline Intercept & 10.91 & 0.49 & 60.77 & 22.21 & $<0.001$ \\
$\log ($ SPC) & -0.76 & 0.08 & 267.07 & -9.43 & $<0.001$ \\
Pseudomonas presence & -3.18 & 0.36 & 267.94 & -8.84 & $<0.001$ \\
Paenibacillus presence & 0.69 & 0.28 & 246.70 & 2.42 & 0.02 \\
Bacillus presence & 0.54 & 0.34 & 245.13 & 1.59 & 0.11 \\
Acinetobacter presence & -1.53 & 0.74 & 272.39 & -2.06 & 0.04 \\
Stenotrophomonas presence & 1.06 & 0.83 & 265.16 & 1.28 & 0.20 \\
Enterococcus presence $_{\text {Enterobacteriaceae presence }}^{7}$ & 0.08 & 0.74 & 246.50 & 0.11 & 0.91 \\
\hline
\end{tabular}

${ }^{1}$ Four of the 280 samples collected and tested did not receive sensory evaluation on d 21 of shelf life due to laboratory error, and were therefore not included in the model.

${ }^{2}$ Parameter estimate of explanatory variable in linear mixed effect model.

${ }^{3}$ Standard error of explanatory variable in linear mixed effect model.

${ }^{4}$ Determined using Satterthwaite approximations.

5 t-statistic of Student's $t$-test for explanatory variable.

${ }^{6} P$-value of Student's $t$-test for explanatory variable.

${ }^{7}$ Determined by $16 \mathrm{~S}$ rDNA sequencing and characterization. 


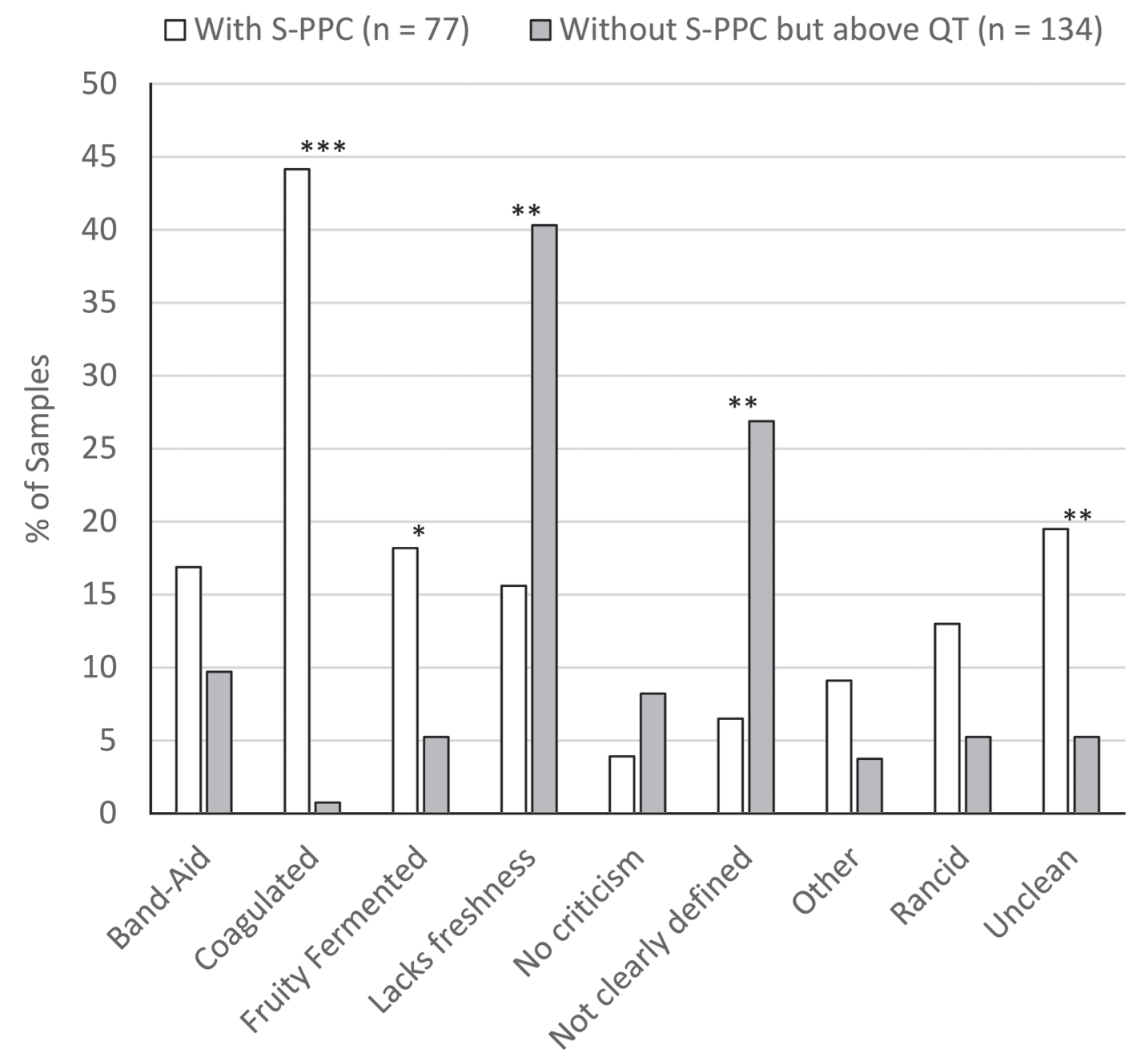

Figure 1. Prevalence of d-21 sensory defects in milk samples with evidence of spoilage due to postpasteurization contamination (S-PPC; sample SPC of $>20,000 \mathrm{cfu} / \mathrm{mL}$ on 1 or more day of testing over $21 \mathrm{~d}$ of shelf-life at $6^{\circ} \mathrm{C}$, and DNA sequencing-confirmed isolation of gram-negative bacterial genera from the sample) and without evidence of S-PPC but above the SPC quality threshold (QT) of $>20,000 \mathrm{cfu} / \mathrm{mL}$. Significance of differences in defect prevalence between samples with S-PPC and samples without S-PPC were determined using Fisher's exact tests and the Holm method for multiple comparison $P$-value correction. ${ }^{*} P<0.1,{ }^{* *} P<0.01$, and ${ }^{* * *} P<0.001$ between samples with and without S-PPC

\section{Repeat Isolation of GN Subtypes Within Facilities}

The number of GN ST isolated from each facility ranged from 2 to 52 , with a median of 17.5 (Table 7). To further organize these data, we identified ST that were isolated from samples collected on multiple visit dates (repeat isolation) and considered an ST to represent sporadic contamination when it was only detected in 1 sample collection at a facility. For 9 of the 10 facilities, we found repeat isolation of 1 or more $16 \mathrm{~S}$ rDNA ST, with a median of $2.5 \mathrm{ST}$ with repeat isolation within a facility and a high of 10 ST with repeat isolation (facility D). For 8 of 10 facilities, we found evidence for repeat isolation of 1 or more ST classified as Pseudomonas. Considering ST from all facilities together, 121 ST were isolated, of which 21 had evidence of repeat isolation within a facility. Among the 21 ST with repeat isolation, $13(62 \%)$ were Pseudomonas, whereas Acinetobacter, Stenotrophomonas, Rahnella, Raoultella, and other genera were each represented by no more than 2 ST with repeat isolation (Table 8).

The $16 \mathrm{~S}$ rDNA sequencing also provided initial data that suggested distinct contamination patterns. For example, at facility D, ST 13 and 16 (both identified as Pseudomonas) were isolated across all 4 sample collections and were isolated repeatedly from $2 \%$, skim, and chocolate milks from gable-top carton filler 2, rotary bottle filler 1 , and rotary bottle filler 2 (Figure 3), suggesting widespread challenges with effective control of Pseudomonas. On the other hand, at facility F, ST 9 was only isolated during 1 sample collection, but for this sample collection (on Aug. 11, 2015) it 


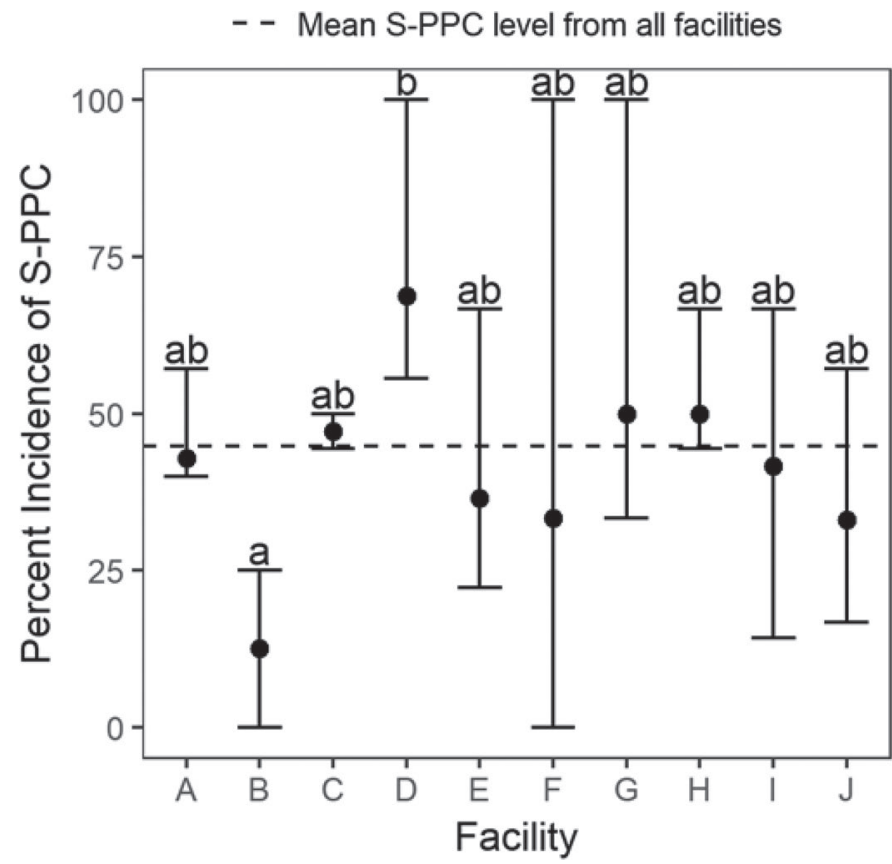

Figure 2. Percent incidence of spoilage due to postpasteurization contamination (S-PPC; sample SPC of $>20,000 \mathrm{cfu} / \mathrm{mL}$ on 1 or more day of testing over $21 \mathrm{~d}$ of shelf-life at $6^{\circ} \mathrm{C}$, and DNA sequencingconfirmed isolation of gram-negative bacterial genera from the sample) in 4 sample collections over approximately 11 mo from 10 northeastern United States dairy processing facilities. Points are the median values; upper and lower bars are the maximum and minimum values, respectively. Facilities that do not have the same letters $(\mathrm{a}, \mathrm{b})$ above their upper bars have significantly different incidences of PPC. was isolated from every sample collected (Figure 4), which suggested a more transient issue, possibly associated with a contamination source early in processing, such as a common pipe or outlet immediately after the pasteurizer. This ST was not identified again following this event, suggesting that it was effectively eliminated by cleaning and sanitation. In addition, at facility C, we isolated ST 85 from 3 skim samples collected from rotary bottle fillers 1, 2, and 3 (on Feb. 8, 2016; Figure 5 ); this ST was obtained from no other samples or on any other sample collection dates at this facility. This suggested an issue specific to skim milk production on this day, which was effectively eliminated by cleaning and sanitation before the subsequent sample collection.

\section{Repeated Isolation of GN ST Across Facilities}

Among the 121 unique ST, 32 (26\%) were isolated from 2 or more of the 10 facilities over the 4 sample collections (Table 9). Among these 32 ST, 19 (59\%) were Pseudomonas, and all but 1 of the Pseudomonas ST was identified as a member of the Pseudomonas fluorescens group. No other single genus was represented by more than 2 ST. Sequence types most commonly associated with S-PPC can be defined as those that are isolated from the greatest number of samplings at the greatest number of facilities. The 3 most common $16 \mathrm{~S}$ rDNA ST that were associated with spoilage were Pseudomonas fluorescens group ST 16 (15 samplings, 8 facilities), Pseudomonas fluorescens group ST 13 (13 samplings,

Table 7. Persistent 16S rDNA sequence types (ST) in 10 northeastern United States fluid milk processing facilities

\begin{tabular}{|c|c|c|c|c|c|c|c|}
\hline Facility & \multicolumn{3}{|c|}{$\begin{array}{l}\text { Number of ST with } \\
\text { repeat isolation over } \\
\mathrm{n} \text { sample collections }\end{array}$} & $\begin{array}{l}\text { Total repeatedly } \\
\text { isolated ST }\end{array}$ & $\begin{array}{l}\text { Total } \\
\text { ST }\end{array}$ & \multicolumn{2}{|c|}{ Persistent ST } \\
\hline A & 1 & 0 & 1 & 2 & 16 & Pseudomonas & 2 \\
\hline B & 0 & 0 & 0 & 0 & 2 & - & 0 \\
\hline $\mathrm{C}$ & 2 & 0 & 0 & 2 & 18 & Acinetobacter & 1 \\
\hline \multirow{3}{*}{$\mathrm{D}$} & & & & & & Rahnella & 1 \\
\hline & & & & & & Raoultella & 1 \\
\hline & & & & & & Stenotrophomonas & 1 \\
\hline \multirow[t]{2}{*}{$\mathrm{E}$} & 2 & 1 & 0 & 3 & 16 & Acinetobacter & 1 \\
\hline & & & & & & Pseudomonas & 2 \\
\hline $\mathrm{F}$ & 1 & 0 & 0 & 1 & 7 & Enterobacter/Kluyvera/Raoultella ${ }^{1}$ & 1 \\
\hline G & 2 & 1 & 0 & 3 & 16 & Pseudomonas & 2 \\
\hline $\mathrm{J}$ & 4 & 0 & 0 & 4 & 21 & Pseudomonas & $\overline{4}$ \\
\hline Median & 2 & 0.5 & 0 & 2.5 & 17.5 & - & - \\
\hline
\end{tabular}

${ }^{1}$ Genera indistinguishable by BLAST query of 16S rDNA ST region against the Ribosomal Database Project database (Cole et al., 2009). 
Table 8. Unique $16 \mathrm{~S}$ rDNA sequence type (ST) counts and occurrence of repeat isolation within a single facility

\begin{tabular}{|c|c|c|}
\hline Genus $^{1}$ & Total unique ST & Repeatedly isolated ST \\
\hline Pseudomonas & 55 & 13 \\
\hline Acinetobacter & 4 & 2 \\
\hline Rahnella & 3 & 1 \\
\hline Raoultella & 3 & 1 \\
\hline Enterobacter/Kluyvera/Raoultella ${ }^{2}$ & 1 & 1 \\
\hline Lelliottia & 1 & 1 \\
\hline Psychrobacter & 1 & 1 \\
\hline Stenotrophomonas & 1 & 1 \\
\hline Ewingella & 7 & 0 \\
\hline Pantoea & 5 & 0 \\
\hline Citrobacter & 4 & 0 \\
\hline Janthinobacterium & 4 & 0 \\
\hline Buttiauxella & 3 & 0 \\
\hline Serratia & 3 & 0 \\
\hline $\operatorname{Rare}^{3}$ & 26 & 0 \\
\hline Total & 121 & 21 \\
\hline
\end{tabular}

${ }^{1}$ Genera identified by BLAST query of 16S rDNA ST region against the Ribosomal Database Project database (Cole et al., 2009).

${ }^{2}$ Genera indistinguishable by BLAST query of $16 \mathrm{~S}$ rDNA ST region against the Ribosomal Database Project database.

${ }^{3} 19$ genera represented by either 1 or 2 ST each.

7 facilities), and Stenotrophomonas rhizophila ST 41 (11 samplings, 8 facilities). Two ST of Acinetobacter, ST 1 and 2, were also moderately common with 6 and 8 samplings (representing 4 and 7 facilities). No ST within the coliforms or EB was isolated from more than 5 samplings.

\section{DISCUSSION}

Although fluid milk spoilage due to PPC has long been recognized as a challenge in the production of HTST-pasteurized fluid milk (Smith, 1920), better data on PPC patterns and their effect on fluid milk quality are needed to allow the industry to make continued improvements in control of PPC. Thus, we used a longitudinal study approach to investigate the causes and effects of spoilage of HTST-pasteurized fluid milk due to PPC in 10 facilities across the northeastern United States. Our data indicate that PPC remains a frequent cause of fluid milk spoilage for samples stored at $6^{\circ} \mathrm{C}$ under conditions mimicking consumer storage. Importantly, our data also indicate that (1) Pseudomonas spp. are the major cause of fluid milk spoilage due to PPC, with GN bacteria typically responsible for severe flavor defects; (2) use of specific strategies for detection of GN bacteria (e.g., CVTA medium), coupled with appropriate milk incubation conditions, is important for sensitive detection of PPC; and (3) PPC problems often are caused by specific spoilage organisms that are repeatedly isolated in a given facility. These findings suggest a need for implementation of improved strategies and technologies for detection and control of PPC, which may be particularly important as fluid milk and other dairy products are distributed to consumers through new channels that can increase product exposure to abuse conditions.

\section{Pseudomonas Are the Major Cause of Fluid Milk S-PPC}

In our study, nearly half of the pasteurized fluid milk samples had evidence of spoilage due to PPC, and Pseudomonas spp. was isolated from over three quarters of samples spoiled due to PPC and over one third of samples overall. This Pseudomonas contamination nearly always was associated with product spoilage through high bacterial counts and the development of sensory defects. Other recent studies have found similarly high contamination frequencies of Pseudomonas in fluid milk from the United States (Ranieri and Boor, 2009; Martin et al., 2011b). In addition to fluid milk, Pseudomonas is well-known to spoil other dairy products, such as fresh, unripened cheeses (Brocklehurst and Lund, 1985; Martin et al., 2011a; Andreani et al., 2015a). The predominance of Pseudomonas in PPC is likely associated with the psychrotolerance and nutritional adaptability of its many species (Fromm and Boor, 2004; Palleroni, 2005a), though this is also true for many dairy spoilage coliforms (Masiello et al., 2016). Pseudomonas possesses enzymes for the digestion of a wide array of organic molecules, and has been shown to catabolize sanitizing compounds, such as quaternary ammonium (Takenaka et al., 2007). Whereas Acinetobacter is similar to Pseudomonas in nutritional versatility, Stenotrophomonas 
REICHLER ET AL.

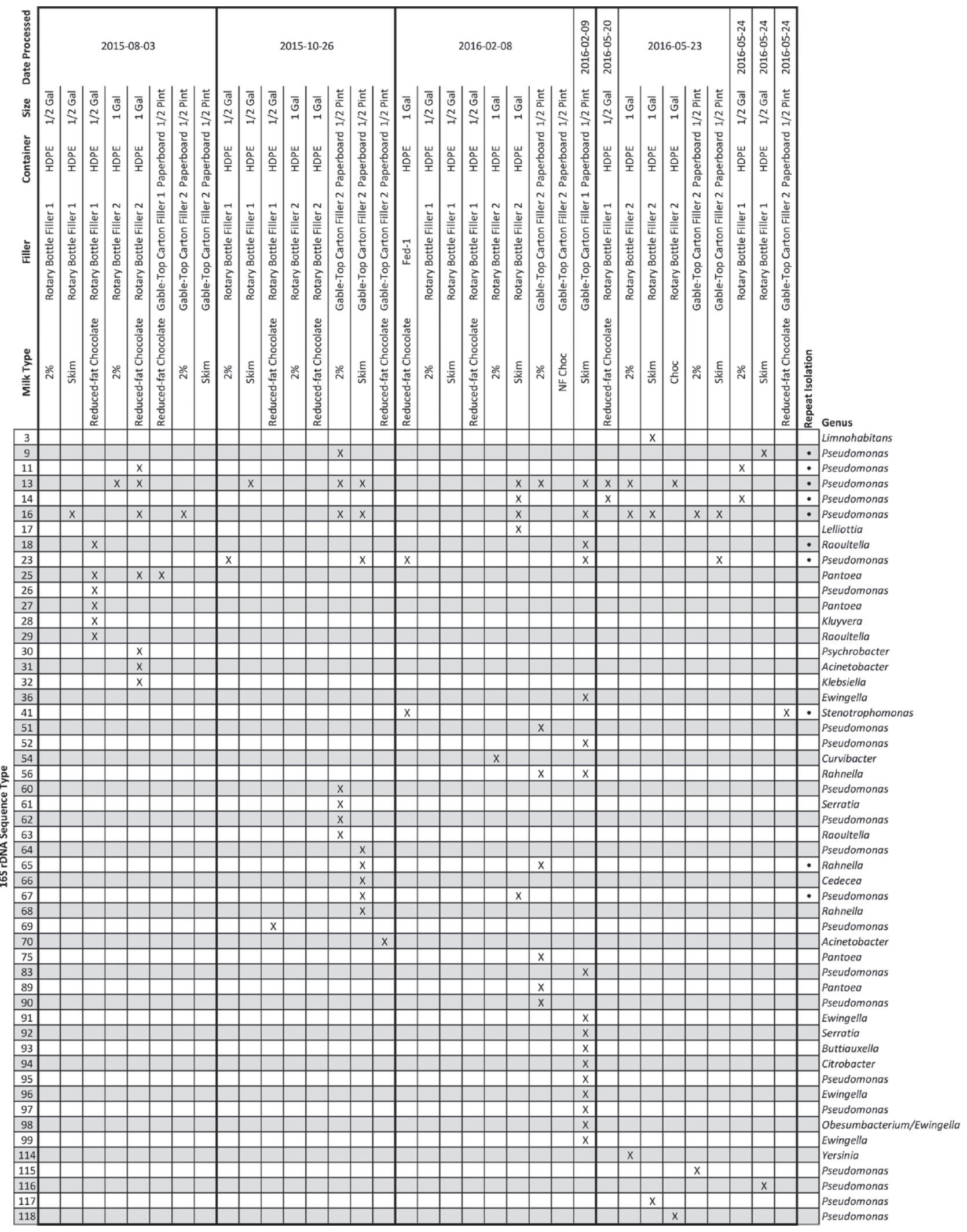

Figure 3. Facility D 16S rDNA sequence type (ST) matrix. Matrix rows represent unique ST, whereas columns represent individual samples of finished product. Heavy vertical lines separate the 4 sample collections. Repeat isolation of ST 13 and 16 from all 4 sample collections and multiple fillers suggests challenges with Pseudomonas control. HDPE = high-density polyethylene. 


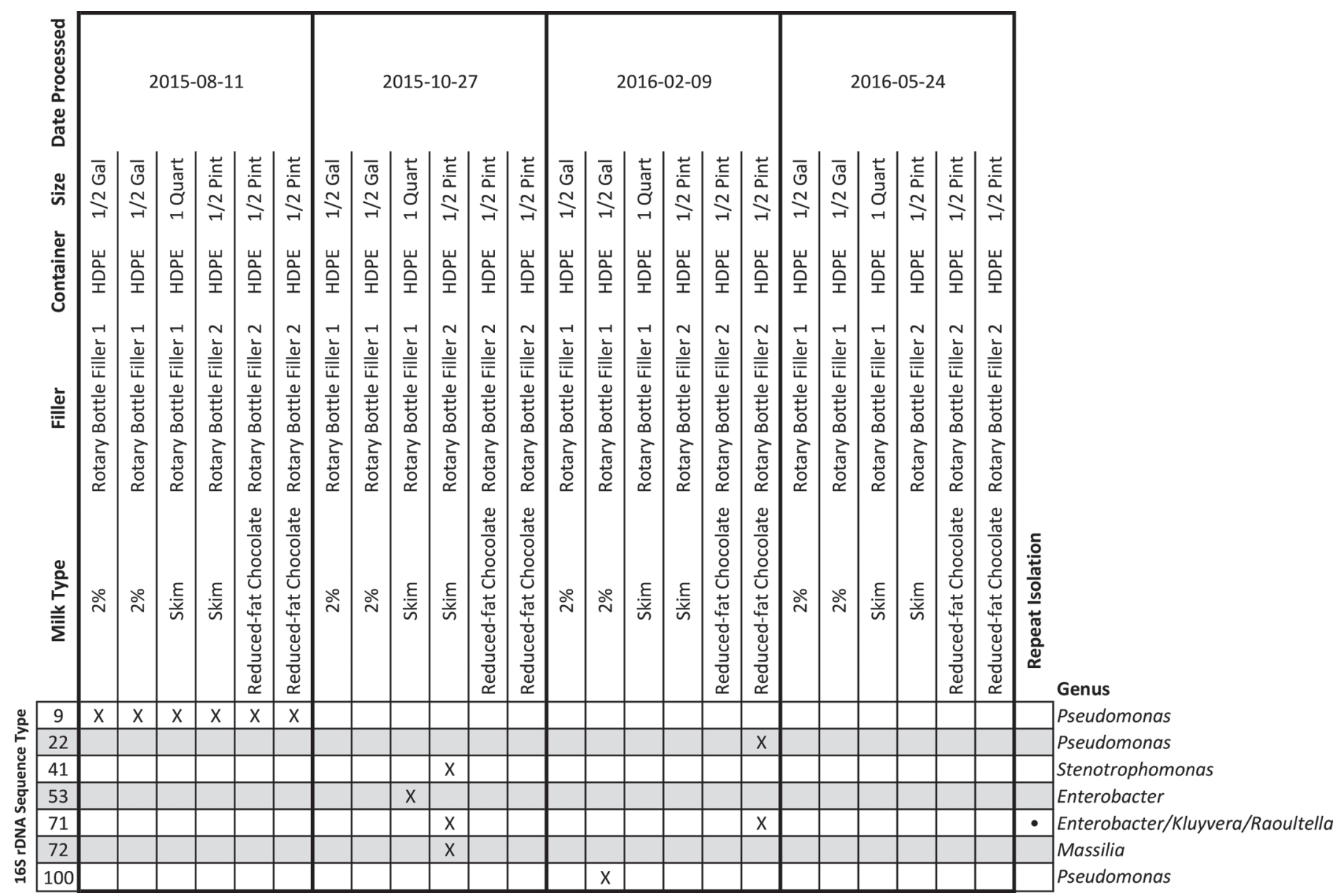

Figure 4. Facility F 16S rDNA sequence type (ST) matrix. Matrix rows represent unique ST, whereas columns represent individual samples of finished product. Heavy vertical lines separate the 4 sample collections. ST 9 was only isolated during 1 sample collection, suggesting a transient contamination source. HDPE = high-density polyethylene.

cannot use galactose and requires specific AA growth factors (Juni, 2005; Palleroni, 2005b), which may have contributed to its lower rates of occurrence and repeat isolation, as well as a lower number of ST.

The observation that a large number of repeatedly isolated ST represent Pseudomonas is also consistent with the well-documented ability of Pseudomonas to form biofilms under many different environmental conditions (Masák et al., 2014), which facilitates their ability to colonize ecological niches in processing facilities and to evade and resist cleaning and sanitation efforts. In addition, the ability of many Pseudomonas to grow at low temperatures (Dogan and Boor, 2003; Palleroni, 2005a) may also contribute to their ability to survive in dairy environments, which often are held at lower temperatures. Acinetobacter and Stenotrophomonas, other non-EB GN psychrotolerant bacteria that were also isolated repeatedly in our study, though to a lesser extent than Pseudomonas, have been reported to be biofilm-formers as well (Di Bonaventura et al., 2004;
McQueary and Actis, 2011). Pseudomonas and Acinetobacter were reported to be the most frequent survivors on meat processing surfaces after cleaning and disinfection (Fagerlund et al., 2017), demonstrating their ability to form resistant biofilms in actual processing facility environments. Overall, our data suggest that effective control of Pseudomonas and, to a lesser extent, other GN spoilage organisms, may not only require strong attention to cleaning, sanitation, and preventive maintenance, but may also require specific strategies to control biofilm formation and to ensure use of sanitizers that are effective against the specific bacterial strains and subtypes found in each facility.

\section{GN Organisms Responsible for PPC Cause More Severe Flavor Defects}

Consistent with previous studies (Schröder et al., 1982; Hayes et al., 2002; Dogan and Boor, 2003), we observed significantly higher levels of sensory defects, 


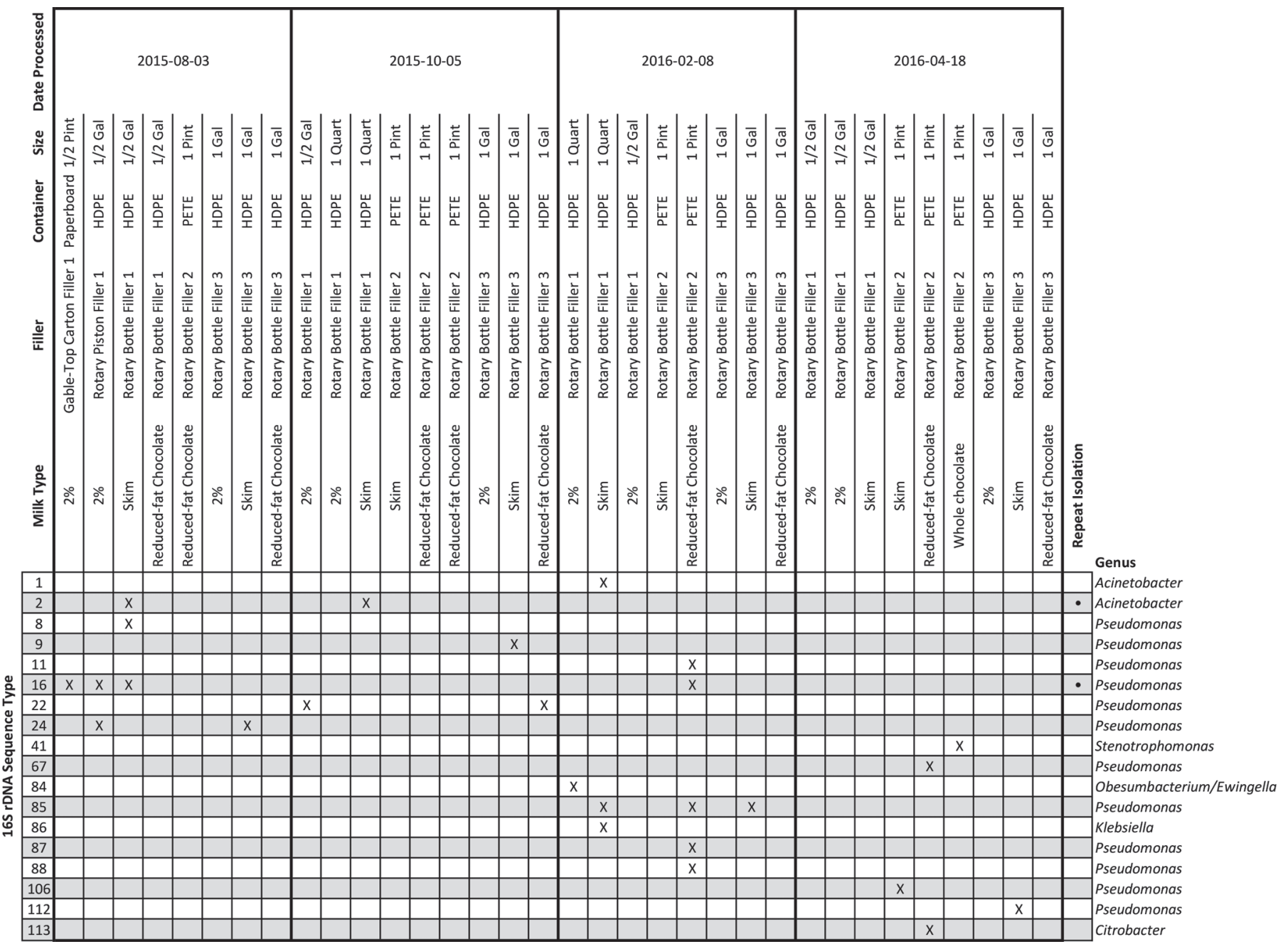

Figure 5. Facility C 16S rDNA sequence type (ST) matrix. Matrix rows represent unique ST, whereas columns represent individual samples of finished product. Heavy vertical lines separate the 4 sample collections; ST 85 was isolated from 3 skim samples collected from rotary bottle fillers 1, 2, and 3 on Feb. 8, 2016, suggesting an issue specific to skim milk production on this date. HDPE = high-density polyethylene. PETE $=$ polyethylene terephthalate.

such as coagulation, fruity/fermented, and unclean, in milk contaminated with GN bacteria. Coagulation, along with off-flavors and off-odors, including cheese, fruit, rancid, and bitter, contribute to negative consumer perception of fluid milk (Martin et al., 2016). Presence of Pseudomonas had the largest and most significant negative effect on overall sample flavor score, with Acinetobacter showing a smaller but still significant negative effect. Presence of EB had a marginally significant negative effect on flavor score, smaller than either Pseudomonas or Acinetobacter. These results are likely due in large part to the diversity of cold-tolerant lipolytic and proteolytic enzymes that Pseudomonas, the most commonly isolated GN genus, can synthesize (Sørhaug and Stepaniak, 1997; Dogan and Boor, 2003). Enterobacteriaceae, though not isolated as frequently in our study, are also known to be capable of and responsible for enzymatic spoilage of fluid milk (Wessels et al., 1989; Masiello et al., 2016). Lower levels of defects were observed in milk samples from which only GP bacteria were isolated. Unlike Pseudomonas contamination, the defects associated with these sporeformers and other GP organisms were less severe than would be expected given their high counts in the milk. Remarkably, coagulation was observed very infrequently for samples lacking PPC, despite the ability of Bacillus and Paenibacillus spp. to synthesize proteolytic enzymes (Cox, 1975; Meer et al., 1991; Hanson et al., 2005). Whereas detection of Paenibacillus or Bacillus did not have a significant negative effect on fluid milk flavor scores, it is possible that extended incubation (past $21 \mathrm{~d}$ ) would to allow for coagulation or other defects due to GP to 
become more pronounced (Cox, 1975; Hanson et al., 2005). Although some defects previously reported to be associated with cold-growing sporeformers (e.g., fruity, acid, unclean, and bitter; Meer et al., 1991) were included in the defect lexicon used here, these defects were rarely identified among samples with no evidence of PPC but with bacterial counts above 20,000 cfu/ $\mathrm{mL}$ (which typically indicated the growth of sporeformers). The high prevalence of not clearly defined defects in these samples suggests that the present milk defect lexicon does not contain all necessary descriptors for off-flavors or odors caused by sporeformer growth.

\section{Repeat Isolation of GN Spoilage Bacteria with Identical 16S rDNA ST Occurs Across Multiple Facilities}

Use of $16 \mathrm{~S}$ rDNA sequence data to define ST for GN bacterial isolates provided initial classification data, which indicated that repeat contamination with specific Pseudomonas strains (and to a much lesser extent other GN bacteria) may be an important contributing factor to PPC in most of the HTST fluid milk processing facilities. We reported evidence for repeat isolation of ST representing GN in 9 of the 10 facilities, with repeat isolation of specific Pseudomonas ST (defined based on partial 16S rDNA sequence) in 8 facilities. Interestingly, members of the EB group only represented a small proportion of strains that showed evidence for repeat isolation. This is consistent with studies that showed persistence of GN spoilage organisms (typically Pseudomonas) in dairy processing facilities and other types of processing facilities (Ralyea et al., 1998; Martin et al., 2011a; Nucera et al., 2016). For example, Ralyea et al. (1998) found that a specific subtype of Pseudomonas (as determined by ribotyping and phenotypic data) persisted in the filler of a dairy facility and was responsible for PPC that significantly reduced HTST milk shelf life. In the past, filling equipment, contaminated air, and contaminated water have been implicated as sources of PPC (Elliker et al., 1964; Schröder, 1984; Gruetmacher and Bradley, 1999). However, only a proportion of repeatedly isolated ST are likely to represent a single specific subtype that persisted in each facility

Table 9. Isolation of identical $16 \mathrm{~S}$ rDNA sequence types (ST) responsible for spoilage due to postpasteurization contamination from multiple facilities

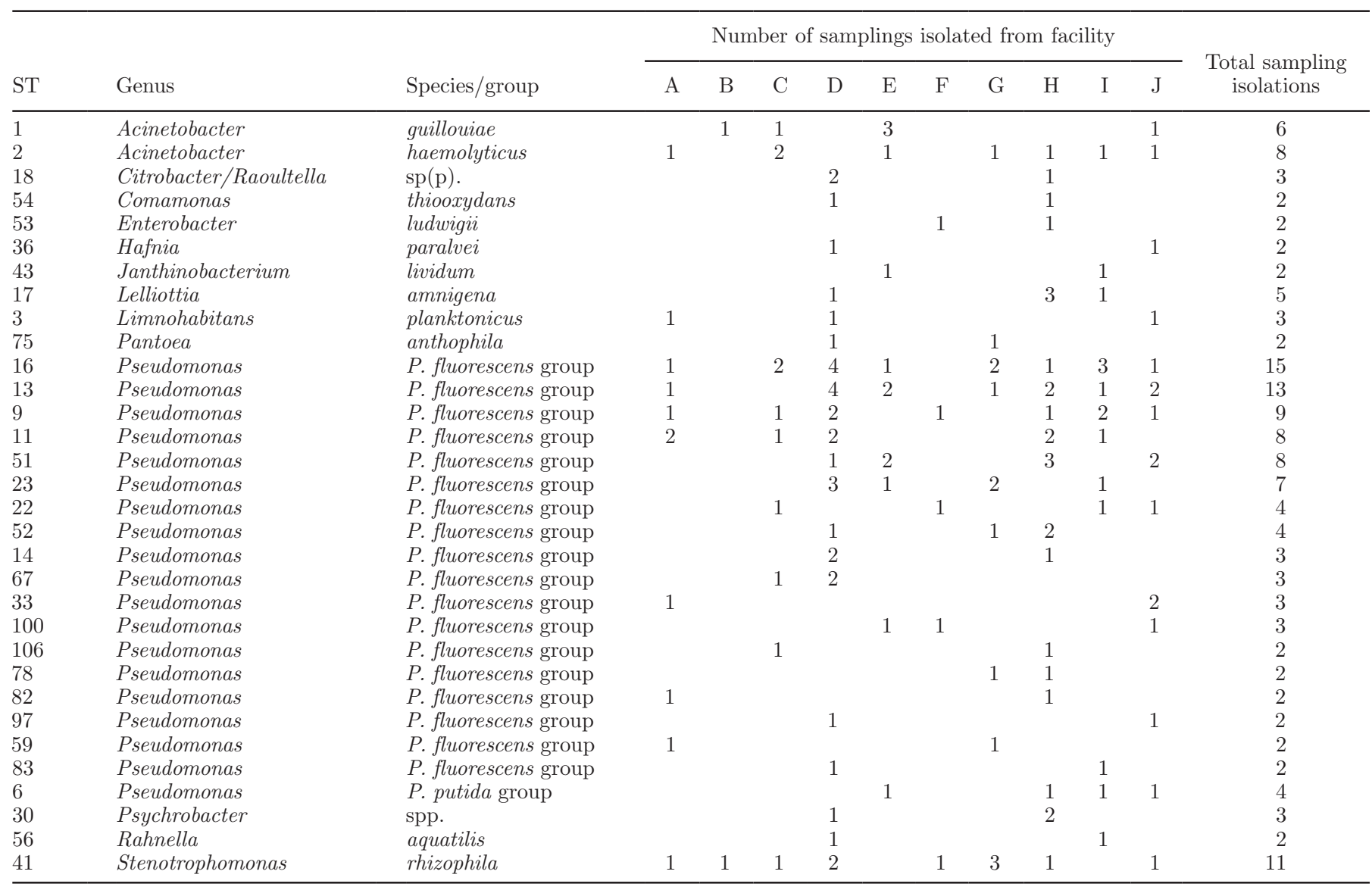


over time; some repeatedly isolated ST may simply represent isolates with the same or closely related species that cannot be differentiated by partial $16 \mathrm{~S}$ rDNA sequencing. This idea is supported by preliminary multilocus sequence typing (MLST) characterization (using the MLST approach reported by Andreani et al., 2015b) of a subset of 4 ST 13 isolates from facility D, which were found to all represent distinct MLST types (unpublished data). However, our data do support that consistent effective control of Pseudomonas represents a major challenge in several facilities. Previous studies that showed persistence of Pseudomonas with discriminatory subtyping methods (e.g., ribotyping, MLST) typically represented reactive troubleshooting efforts that involved sampling of a single facility over shorter periods, typically less than 4 mo (Ralyea et al., 1998; Martin et al., 2011a). In contrast, the prospective study reported here included multiple facilities and provides new data on the difficulty of consistently controlling Pseudomonas across an industry cross section.

Our findings on spoilage organisms are also consistent with a large body of knowledge that other bacteria, and particularly Listeria monocytogenes, can persist in processing facilities, including dairy processing facilities, for extended times, sometimes exceeding years or even decades (Kabuki et al., 2004; Vongkamjan et al., 2013). Whereas several clear differences exist between GN spoilage organisms (particularly Pseudomonas) and Listeria monocytogenes (e.g., Pseudomonas exhibits more frequent sanitizer resistance), some of the industry lessons learned from efforts to eliminate L. monocytogenes persistence may be applicable for control of persistent spoilage organisms. For example, persistence of L. monocytogenes in niches (i.e., locations that are not reached by sanitizer due to equipment or building design issues or incomplete breakdown during sanitation) has frequently been linked to L. monocytogenes persistence, and several industry guidance documents detail procedures that can be used to identify and eliminate niches (Tompkin, 2002; Malley et al., 2015). A reevaluation of the sanitary design of equipment, such as valves and fillers, with subsequent design improvements or changes to sanitation procedures (e.g., enhanced equipment breakdown before sanitation) may facilitate improved elimination of Pseudomonas and other spoilage bacteria in dairy processing facilities.

Although repeat isolation of ST within facilities increases our understanding of PPC spoilage patterns and suggests opportunities for better control, isolation of identical ST between facilities serves as an overall indicator of the broad distribution of Pseudomonas in the dairy environment and in refrigerated fluid milk. Over half of ST isolated from multiple facilities represented Pseudomonas, and specifically the Pseudomonas fluorescens group, which has been reported to consist of at least 52 closely related species (Mulet et al., 2010). This group is known to contaminate a wide variety of foods, including vegetables, fish, meat, and dairy products (Andreani et al., 2015b). Interestingly, only $1 \mathrm{ST}$ of Pseudomonas from outside the P. fluorescens group was isolated from multiple facilities. Sequence type 6 was identified as a member of the Pseudomonas putida group, another group commonly responsible for food spoilage (Ralyea et al., 1998; Dogan and Boor, 2003; Stellato et al., 2017).

\section{CVTA Provides for Sensitive Detection of PPC}

Our data show that CVTA could detect the presence of PPC organisms in nearly every sample confirmed to contain GN bacteria by DNA sequencing of isolates collected over shelf life. No sample that tested negative on CVTA yielded sequence-confirmed GN bacteria on any other medium (SPC and coliform and EB Petrifilms). Whereas this suggests that CVTA has a high sensitivity for the GN bacteria typically present in pasteurized fluid milk, it has been demonstrated in other experiments that CVTA is not an infallible medium and it may not detect select strains in pure culture within several important genera, notably Acinetobacter, Pseudomonas, Vibrio, Yersinia, and Escherichia (Hervert et al., 2016). In our study, CVTA testing did yield positive results with 18 samples in which we were unable to confirm the presence of GN bacteria. The majority of these false positives were attributed to Paenibacillus, which often stains gram-variable, and therefore may not be vulnerable to the selective agent, crystal violet, in the medium (Priest, 2009). Although these results are consistent with previous studies that reported the usefulness of CVTA for detection of PPC, and its inability to inhibit some GP spoilage organisms (Sing et al., 1967), CVTA remains a well-established medium with broad sensitivity for total GN bacteria (Hervert et al., 2016). However, use of CVTA remains beyond the capability of many processors, as preparation requires an autoclave as well as poststerilization aseptic addition of the 2,3,5-triphenyltetrazolium chloride supplement. It also requires spread- or pour-plating techniques, which are beyond the capabilities of many processing facility laboratories (Frank and Yousef, 2004). Even considering these challenges, CVTA can be a valuable tool for culture-based detection of PPC, particularly in processing facilities with more sophisticated laboratory operations.

To our knowledge, neither prepoured CVTA plates nor other convenient in-facility culture-based tests for total GN bacteria [e.g., 3M Petrifilm, Compact Dry by Hardy Diagnostics (Santa Maria, CA), NeoFilm 
(Neogen, Lansing, MI), and so on], are currently available, and no automated or rapid-detection platforms for the same purpose are validated for rapid detection of total GN organisms in milk. The unavailability of appropriate media for detection of total GN organisms, including Pseudomonas, is likely a contributing factor that prevents processors from detecting and addressing quality issues related to this group of bacteria. Until such tests are available, processors may be able to use alternative, typically less reliable or rapid strategies (many of which are summarized by Coghill and Juffs, 1979) to assess milk for the presence of PPC bacteria.

\section{Current Practices and Testing May Underestimate Effects of PPC on Product Quality}

As demonstrated here and in previous experiments (Elliker, 1968; Watrous et al., 1971; Hankin and Stephens, 1972), sole reliance on SPC and coliform count testing of fluid milk immediately after production, as is typically done in large fluid milk processing facilities, likely will not reveal any but the most severe PPC issues. These tests are of limited use in detecting lowlevel Pseudomonas or other GN psychrotolerant contaminants that may cause spoilage over shelf life, even if present at levels well below 1 MPN (most probable number)/mL immediately after filling (Schröder et al., 1982). The need, in the United States, of performing in-facility coliform testing on finished product to ensure compliance with regulations has likely allowed facilities to more effectively address issues of coliform contamination in their products. This could, in part, explain the relatively low incidence of coliforms detected over shelf life in this and other studies (Martin et al., 2012). Whereas many facilities do not perform microbiological tests on their milk following initial tests performed immediately after processing, they may assess shelf life by performing a basic pass or fail sensory evaluation on, or several days past, the product code date. Based on our interactions with processing facilities, product stored for this evaluation is typically kept in unopened, full containers at 4 to $6^{\circ} \mathrm{C}$. This approach has several shortfalls. First, storage at $4^{\circ} \mathrm{C}$ may not reflect the mild temperature abuse that fluid milk may be exposed to during transport and consumer storage (Kosa et al., 2007; Elliker, 1968). Second, full containers provide very little oxygen-containing headspace, which may reduce the growth of Pseudomonas and other obligately aerobic, psychrotolerant GN bacteria (Sinclair and Stokes, 1963; Brandt and Ledford, 1982). Limited oxygen-containing headspace may also affect expression of bacterial phenotypes important for spoilage (Bassette et al., 1986), as supported by several reports that, in the absence of sufficient oxygen, Pseudomonas spp. will not produce a color defect (Price-Whelan et al., 2007; Andreani et al., 2015b; Evanowski et al., 2017). Improved sensitivity of shelf-life tests for detecting PPC could thus be achieved by storage $\left(\right.$ at $6^{\circ} \mathrm{C}$ ) of partially filled containers or by aseptic transfer of 1 or more aliquots of milk to sterile containers with ample headspace, as done in our study.

\section{CONCLUSIONS}

Despite overall improvements in fluid milk quality and shelf life, detection and control of PPC remains an important challenge in the production of HTST-pasteurized fluid milk. Pseudomonas is not only the most common cause of PPC, particularly in facilities that have traditionally focused on control of coliforms, but also causes many severe defects, including coagulation as well as flavor, odor, and color defects. Consequently, there is a need to develop and apply improved approaches to detect PPC and identify PPC sources, including improved rapid-detection methods as well as subtyping methods such as MLST or whole genome sequencing. Although unlikely to be used routinely at this time, use of subtyping methods will greatly enhance our ability to identify PPC sources, such as specific fillers, lines, or tanks, facilitating corrective actions and long-term improvements, for example through improved sanitary equipment design.

\section{ACKNOWLEDGMENTS}

This work was funded by the National Dairy Council (Rosemont, IL; OSP \# 73849) and by the New York State Milk Promotion Advisory Board (Albany, NY; OSP \# 83562) through the New York State Department of Agriculture and Markets (Albany, NY). We wish to thank the students, faculty, and staff of the Cornell University Milk Quality Improvement Program, the Cornell University Food Safety Laboratory, and the Cornell University Dairy Extension for their work to support this project. We also wish to thank the participating fluid milk processing facilities for their continued willingness to collaborate with us on this and other projects.

\section{REFERENCES}

Andreani, N. A., L. Carraro, M. E. Martino, M. Fondi, L. Fasolato, G. Miotto, M. Magro, F. Vianello, and B. Cardazzo. 2015a. A genomic and transcriptomic approach to investigate the blue pigment phenotype in Pseudomonas fluorescens. Int. J. Food Microbiol. 213:88-98. https://doi.org/10.1016/j.ijfoodmicro.2015.05.024.

Andreani, N. A., M. E. Martino, L. Fasolato, L. Carraro, F. Montemurro, R. Mioni, P. Bordin, and B. Cardazzo. 2015b. Reprint of 'Tracking the blue: A MLST approach to characterise the Pseudomonas fluorescens group'. Food Microbiol. 45:148-158. https://doi .org/10.1016/j.fm.2014.11.011. 
Bassette, R., D. Y. C. Fung, V. R. Mantha, and E. H. Marth. 1986. Off-flavors in milk. Crit. Rev. Food Sci. Nutr. 24:1-52. https://doi .org/10.1080/10408398609527439.

Bates, D., M. Mächler, B. Bolker, and S. Walker. 2015. Fitting linear mixed-effects models using lme4. J. Stat. Softw. 67:1-48. https:// doi.org/10.18637/jss.v067.i01.

Brandt, M. J., and R. A. Ledford. 1982. Influence of milk aeration on growth of psychrotrophic pseudomonads. J. Food Prot. 45:132134. https://doi.org/10.4315/0362-028X-45.2.132.

Brocklehurst, T. F., and B. M. Lund. 1985. Microbiological changes in cottage cheese varieties during storage at $+7^{\circ} \mathrm{c}$. Food Microbiol. 2:207-233. https://doi.org/10.1016/0740-0020(85)90036-X.

Buzby, J. C., H. Farah-Wells, and J. Hyman. 2014. The estimated amount, value, and calories of postharvest food losses at the retail and consumer levels in the United States. USDA-ERS Economic Information Bulletin Number 121. Accessed Apr. 24, 2018. https://ssrn.com/abstract $=2501659$.

Coghill, D., and H. Juffs. 1979. Comparison of the Moseley keeping quality test for pasteurised milk and cream products with other tests of shorter duration. Aust. J. Dairy Technol. 34:118-120.

Cole, J. R., Q. Wang, E. Cardenas, J. Fish, B. Chai, R. J. Farris, A. S. Kulam-Syed-Mohideen, D. M. McGarrell, T. Marsh, G. M. Garrity, and J. M. Tiedje. 2009. The ribosomal database project: Improved alignments and new tools for rRNA analysis. Nucleic Acids Res. 37:D141-D145. https://doi.org/10.1093/nar/gkn879.

Cox, W. A. 1975. Subject: Bitty cream and related problems: Problems associated with bacterial spores in heat-treated milk and dairy products. Int. J. Dairy Technol. 28:59-68. https://doi.org/ 10.1111/j.1471-0307.1975.tb00682.x.

Dabbah, R., W. A. Moats, and V. M. Edwards. 1971. Heat survivor curves of food-borne bacteria suspended in commercially sterilized whole milk. II. Bacteria other than salmonellae. J. Dairy Sci. 54:1772-1779. https://doi.org/10.3168/jds.S0022-0302(71)86111 $-8$.

Davidson, P. M., L. A. Roth, and S. A. Gambrel-Lenarz. 2004. Coliform and other indicator bacteria. Pages 187-226 in Standard Methods for the Examination of Dairy Products. 17 ed. H. M. Wehr and J. F. Frank, ed. American Public Health Association, Washington, DC

Di Bonaventura, G., I. Spedicato, D. D'Antonio, I. Robuffo, and R Piccolomini. 2004. Biofilm formation by Stenotrophomonas maltophilia: Modulation by quinolones, trimethoprim-sulfamethoxazole, and ceftazidime. Antimicrob. Agents Chemother. 48:151-160. https://doi.org/10.1128/AAC.48.1.151-160.2004.

Dogan, B., and K. J. Boor. 2003. Genetic diversity and spoilage potentials among Pseudomonas spp. isolated from fluid milk products and dairy processing plants. Appl. Environ. Microbiol. 69:130-138. https://doi.org/10.1128/aem.69.1.130-138.2003

Elliker, P. R. 1968. Shelf-life of food products. American Dairy Review 30:80-81

Elliker, P. R., E. L. Sing, L. J. Christensen, and W. E. Sandine. 1964. Psychrophilic bacteria and keeping quality of pasteurized dairy products. J. Milk Food Technol. 27:69-75.

Eneroth, A.. B. Svensson, G. Molin, and A. Christiansson. 2001. Contamination of pasteurized milk by Bacillus cereus in the filling machine. J. Dairy Res. 68:189-196. https://doi.org/10.1017/ S002202990100485X

Evanowski, R. L., S. J. Reichler, D. J. Kent, N. H. Martin, K. J. Boor, and M. Wiedmann. 2017. Short communication: Pseudomonas azotoformans causes gray discoloration in HTST fluid milk. J. Dairy Sci. 100:7906-7909. https://doi.org/10.3168/jds.2017-12650.

Fagerlund, A., T. Møretrø, E. Heir, R. Briandet, and S. Langsrud. 2017. Cleaning and disinfection of biofilms composed of Listeria monocytogenes and background microbiota from meat processing surfaces. Appl. Environ. Microbiol. 83:e01046-17. https://doi.org/ 10.1128/AEM.01046-17.

FDA. 2015. Grade "A" Pasteurized Milk Ordinance. Food and Drug Administration (FDA), Washington, DC.

Frank, J. F., and A. E. Yousef. 2004. Tests for groups of microorganisms. Pages 227-248 in Standard Methods for the Examination of
Dairy Products. 17 ed. H. M. Wehr and J. F. Frank, ed. American Public Health Association, Washington, DC.

Fromm, H. I., and K. J. Boor. 2004. Characterization of pasteurized fluid milk shelf-life attributes. J. Food Sci. 69:M207-M214. https://doi.org/10.1111/j.1365-2621.2004.tb09889.x.

Greisen, K., M. Loeffelholz, A. Purohit, and D. Leong. 1994. PCR primers and probes for the 16s rRNA gene of most species of pathogenic bacteria, including bacteria found in cerebrospinal fluid. J. Clin. Microbiol. 32:335-351.

Gruetmacher, T. J., and R. L. Bradley. 1999. Identification and control of processing variables that affect the quality and safety of fluid milk. J. Food Prot. 62:625-631. https://doi.org/10.4315/0362 $-028 \mathrm{X}-62.6 .625$.

Gustavsson, J., C. Cederberg, U. Sonesson, R. Van Otterdijk, and A. Meybeck. 2011. Global Food Losses and Food Waste. FAO, Rome, Italy.

Hankin, L., and G. R. Stephens. 1972. What tests usefully predict keeping quality of perishable foods? J. Milk Food Technol. 35:574576. https://doi.org/10.4315/0022-2747-35.10.574.

Hanson, M. L., W. L. Wendorff, and K. B. Houck. 2005. Effect of heat treatment of milk on activation of Bacillus spores. J. Food Prot. 68:1484-1486. https://doi.org/10.4315/0362-028X-68.7.1484.

Harwalkar, V. R., H. Cholette, R. C. McKellar, and D. B. Emmons. 1993. Relation between proteolysis and astringent off-flavor in milk. J. Dairy Sci. 76:2521-2527. https://doi.org/10.3168/jds .S0022-0302(93)77587-6.

Hayes, W., C. H. White, and M. A. Drake. 2002. Sensory aroma characteristics of milk spoilage by Pseudomonas species. J. Food Sci 67:448-454. https://doi.org/10.1111/j.1365-2621.2002.tb11427.x.

Hervert, C. J., A. S. Alles, N. H. Martin, K. J. Boor, and M. Wiedmann. 2016. Evaluation of different methods to detect microbial hygiene indicators relevant in the dairy industry. J. Dairy Sci. 99:7033-7042. https://doi.org/10.3168/jds.2016-11074.

Hervert, C. J., N. H. Martin, K. J. Boor, and M. Wiedmann. 2017. Survival and detection of coliforms, Enterobacteriaceae, and Gram-negative bacteria in greek yogurt. J. Dairy Sci. 100:950-960. https://doi.org/10.3168/jds.2016-11553.

Imhoff, J. F. 2005. Enterobacteriales. Pages 587-850 in Bergey's Manual of Systematic Bacteriology: Vol. 2: The Proteobacteria. 2nd ed. D. J. Brenner, N. R. Krieg, J. T. Staley, ed. Springer US, Boston, MA.

Ivy, R. A., M. L. Ranieri, N. H. Martin, H. C. den Bakker, B. M. Xavier, M. Wiedmann, and K. J. Boor. 2012. Identification and characterization of psychrotolerant sporeformers associated with fluid milk production and processing. Appl. Environ. Microbiol. 78:1853-1864. https://doi.org/10.1128/AEM.06536-11.

Juni, E. 2005. Acinetobacter. Pages 425-437 in Bergey's Manual of Systematic Bacteriology. Vol. 2: The Proteobacteria. 2 ed. D. J. Brenner, N. R. Krieg, and J. T. Staley, ed. Springer US, Boston, MA.

Kabuki, D. Y., A. Y. Kuaye, M. Wiedmann, and K. J. Boor. 2004. Molecular subtyping and tracking of Listeria monocytogenes in latinstyle fresh-cheese processing plants. J. Dairy Sci. 87:2803-2812. https://doi.org/10.3168/jds.S0022-0302(04)73408-6.

Kosa, K. M., S. C. Cates, S. Karns, S. L. Godwin, and D. Chambers. 2007. Consumer home refrigeration practices: Results of a web-based survey. J. Food Prot. 70:1640-1649. https://doi.org/10 $.4315 / 0362-028 \mathrm{x}-70.7 .1640$.

Kuznetsova, A., P. B. Brockhoff, and R. H. B. Christensen. 2017. Lmertest package: Tests in linear mixed effects models. J. Stat. Softw. 82:1-26. https://doi.org/10.18637/jss.v082.i13.

Laird, D. T., S. A. Gambrel-Lenarz, F. M. Scher, T. E. Graham, and R. Reddy. 2004. Microbiological count methods. Pages 153-186 in Standard Methods for the Examination of Dairy Products. 17 ed. H. M. Wehr and J. F. Frank, ed. American Public Health Association, Washington, DC.

Larsson, A. 2014. Aliview: A fast and lightweight alignment viewer and editor for large datasets. Bioinformatics 30:3276-3278. https://doi .org/10.1093/bioinformatics/btu531. 
Lenth, R. V. 2016. Least squares means: The R package lsmeans. J. Stat. Softw. 69:33. https://doi.org/10.18637/jss.v069.i01.

Macaulay, D. M., R. Z. Hawirko, and N. James. 1963. Effect of pasteurization on survival of certain psychrophilic bacteria. Appl. Microbiol. 11:90-92.

Malley, T. J. V., J. Butts, and M. Wiedmann. 2015. Seek and destroy process: Listeria monocytogenes process controls in the ready-toeat meat and poultry industry. J. Food Prot. 78:436-445. https:// doi.org/10.4315/0362-028X.JFP-13-507.

Martin, N., N. Carey, S. Murphy, D. Kent, J. Bang, T. Stubbs, M. Wiedmann, and R. Dando. 2016. Exposure of fluid milk to LED light negatively affects consumer perception and alters underlying sensory properties. J. Dairy Sci. 99:4309-4324. https://doi.org/10 .3168/jds.2015-9603.

Martin, N. H., N. R. Carey, S. C. Murphy, M. Wiedmann, and K. J. Boor. 2012. A decade of improvement: New York State fluid milk quality. J. Dairy Sci. 95:7384-7390. https://doi.org/10.3168/jds $.2012-5767$.

Martin, N. H., S. C. Murphy, R. D. Ralyea, M. Wiedmann, and K. J. Boor. 2011a. When cheese gets the blues: Pseudomonas fluorescens as the causative agent of cheese spoilage. J. Dairy Sci. 94:31763183. https://doi.org/10.3168/jds.2011-4312.

Martin, N. H., M. L. Ranieri, S. C. Murphy, R. D. Ralyea, M. Wiedmann, and K. J. Boor. 2011b. Results from raw milk microbiological tests do not predict the shelf-life performance of commercially pasteurized fluid milk. J. Dairy Sci. 94:1211-1222. https://doi .org/10.3168/jds.2010-3915.

Masák, J., A. Čejková, O. Schreiberová, and T. Řezanka. 2014. Pseudomonas biofilms: Possibilities of their control. FEMS Microbiol. Ecol. 89:1-14. https://doi.org/10.1111/1574-6941.12344.

Masiello, S. N., D. Kent, N. H. Martin, Y. H. Schukken, M. Wiedmann, and K. J. Boor. 2017. Longitudinal assessment of dairy farm management practices associated with the presence of psychrotolerant Bacillales spores in bulk tank milk on 10 New York State dairy farms. J. Dairy Sci. 100:8783-8795. https://doi.org/10 .3168/jds.2017-13139.

Masiello, S. N., N. H. Martin, A. Trmčić, M. Wiedmann, and K. J. Boor. 2016. Identification and characterization of psychrotolerant coliform bacteria isolated from pasteurized fluid milk. J. Dairy Sci. 99:130-140. https://doi.org/10.3168/jds.2015-9728.

McQueary, C. N., and L. A. Actis. 2011. Acinetobacter baumannii biofilms: Variations among strains and correlations with other cell properties. J. Microbiol. 49:243-250. https://doi.org/10.1007/ s12275-011-0343-7.

Meer, R. R., J. Baker, F. W. Bodyfelt, and M. W. Griffiths. 1991. Psychrotrophic Bacillus spp. in fluid milk products: A review. J. Food Prot. 54:969-979. https://doi.org/10.4315/0362-028x-54.12.969.

Miller, R. A., D. J. Kent, K. J. Boor, N. H. Martin, and M. Wiedmann. 2015a. Different management practices are associated with mesophilic and thermophilic spore levels in bulk tank raw milk. J. Dairy Sci. 98:4338-4351. https://doi.org/10.3168/jds.2015-9406.

Miller, R. A., D. J. Kent, M. J. Watterson, K. J. Boor, N. H. Martin, and M. Wiedmann. 2015b. Spore populations among bulk tank raw milk and dairy powders are significantly different. J. Dairy Sci. 98:8492-8504. https://doi.org/10.3168/jds.2015-9943.

Mulet, M., J. Lalucat, and E. García-Valdés. 2010. DNA sequencebased analysis of the Pseudomonas species. Environ. Microbiol. 12:1513-1530. https://doi.org/10.1111/j.1462-2920.2010.02181.x.

Nogarol, C., P. L. Acutis, D. M. Bianchi, C. Maurella, S. Peletto, S. Gallina, D. Adriano, F. Zuccon, S. Borrello, M. Caramelli, and L. Decastelli. 2013. Molecular characterization of Pseudomonas fluorescens isolates involved in the Italian "blue mozzarella" event. J. Food Prot. 76:500-504. https://doi.org/10.4315/0362-028X.JFP $-12-312$.

Nucera, D. M., S. Lomonaco, P. Morra, M. F. Ortoffi, D. Giaccone, and M. A. Grassi. 2016. Dissemination and persistence of Pseudomonas spp. in small-scale dairy farms. Ital. J. Food Saf. 5:5652. https://doi.org/10.4081/ijfs.2016.5652.

Palleroni, N. J. 2005a. Pseudomonas. Pages 323-379 in Bergey's Manual of Systematic Bacteriology. Vol. 2: The Proteobacteria. 2 ed.
D. J. Brenner, N. R. Krieg, and J. T. Staley, ed. Springer US, Boston, MA.

Palleroni, N. J. 2005b. Stenotrophomonas. Pages 323-379 in Bergey's Manual of Systematic Bacteriology. Vol. 2: The Proteobacteria. 2 ed. D. J. Brenner, N. R. Krieg, and J. T. Staley, ed. Springer US, Boston, MA.

Price-Whelan, A., L. E. P. Dietrich, and D. K. Newman. 2007. Pyocyanin alters redox homeostasis and carbon flux through central metabolic pathways in Pseudomonas aeruginosa pa14. J. Bacteriol. 189:6372-6381. https://doi.org/10.1128/JB.00505-07.

Priest, F. G. 2009. Paenibacillus. Pages 269-297 in Bergey's Manual of Systematic Bacteriology. Vol 3: The Firmicutes. 2 ed. P. D. Vos, G. M. Garrity, D. Jones, N. R. Krieg, W. Ludwig, F. A. Rainey, K. Schleifer, and W. B. Whitman, ed. Springer US, Boston, MA.

Priyam, A., B. J. Woodcroft, V. Rai, A. Munagala, I. Moghul, F. Ter, M. A. Gibbins, H. Moon, G. Leonard, W. Rumpf, and Y. Wurm. 2015. SequenceServer: A modern graphical user interface for custom BLAST databases. bioRxiv. https://doi.org/10.1101/033142.

Punch, J. D., J. C. Olson, and E. L. Thomas. 1965. Psychrophilic bacteria. III. Population levels associated with flavor or physical change in milk. J. Dairy Sci. 48:1179-1183.

Ralyea, R. D., M. Wiedmann, and K. J. Boor. 1998. Bacterial tracking in a dairy production system using phenotypic and ribotyping methods. J. Food Prot. 61:1336-1340. https://doi.org/10.4315/ 0362-028X-61.10.1336.

Randolph, H. E., B. K. Chakraborty, O. Hampton, and D. L. Bogart. 1973. Microbial counts of individual producer and commingled grade A raw milk. J. Milk Food Technol. 36:146-151. https://doi .org/10.4315/0022-2747-36.3.146.

Ranieri, M. L., and K. J. Boor. 2009. Short communication: Bacterial ecology of high-temperature, short-time pasteurized milk processed in the United States. J. Dairy Sci. 92:4833-4840. https:// doi.org/10.3168/jds.2009-2181.

Rothman, R. E., M. D. Majmudar, G. D. Kelen, G. Madico, C. A. Gaydos, T. Walker, and T. C. Quinn. 2002. Detection of bacteremia in emergency department patients at risk for infective endocarditis using universal $16 \mathrm{~S}$ rRNA primers in a decontaminated polymerase chain reaction assay. J. Infect. Dis. 186:1677-1681. https://doi.org/10.1086/345367.

Salustiano, V. C., N. J. Andrade, N. F. F. Soares, J. C. Lima, P. C. Bernardes, L. M. P. Luiz, and P. E. Fernandes. 2009. Contamination of milk with Bacillus cereus by post-pasteurization surface exposure as evaluated by automated ribotyping. Food Control 20:439-442. https://doi.org/10.1016/j.foodcont.2008.07.004.

Schröder, M. J. 1984. Origins and levels of post pasteurization contamination of milk in the dairy and their effects on keeping quality. J. Dairy Res. 51:59-67. https://doi.org/10.1017/S0022029900023323.

Schröder, M. J. A., C. M. Cousins, and C. H. McKinnon. 1982. Effect of psychrotrophic post-pasteurization contamination on the keeping quality at 11 and $5^{\circ} \mathrm{C}$ of HTST-pasteurized milk in the UK. J. Dairy Res. 49:619-630. https://doi.org/10.1017/ S0022029900022767.

Seitz, E. W., P. R. Elliker, and W. E. Sandine. 1961. A pigmentproducing spoilage bacterium responsible for violet discoloration of refrigerated market milk and cream. Appl. Microbiol. 9:287-290.

Sinclair, N. A., and J. L. Stokes. 1963. Role of oxygen in the high cell yields of psychrophiles and mesophiles at low temperatures. J. Bacteriol. 85:164-167.

Sing, E. L., P. R. Elliker, L. J. Christensen, and W. E. Sandine. 1967. Effective testing procedures for evaluating plant sanitation. J. Milk Food Technol. 30:103-111. https://doi.org/10.4315/0022 -2747-30.4.103.

Smith, R. S. 1920. Bacterial control in milk plants. J. Dairy Sci. 3:540554. https://doi.org/10.3168/jds.S0022-0302(20)94297-2.

Sørhaug, T., and L. Stepaniak. 1997. Psychrotrophs and their enzymes in milk and dairy products: Quality aspects. Trends Food Sci. Technol. 8:35-41. https://doi.org/10.1016/S0924-2244(97)01006-6.

Stellato, G., D. R. Utter, A. Voorhis, M. De Angelis, A. M. Eren, and D. Ercolini. 2017. A few Pseudomonas oligotypes dominate in 
the meat and dairy processing environment. Front. Microbiol. 8. https://doi.org/10.3389/fmicb.2017.00264.

Stucky, B. J. 2012. Seqtrace: A graphical tool for rapidly processing DNA sequencing chromatograms. J. Biomol. Tech. 23:90-93. https://doi.org/10.7171/jbt.12-2303-004.

Takenaka, S., T. Tonoki, K. Taira, S. Murakami, and K. Aoki. 2007. Adaptation of Pseudomonas sp. strain 7-6 to quaternary ammonium compounds and their degradation via dual pathways. Appl. Environ. Microbiol. 73:1797-1802. https://doi.org/10.1128/AEM .02426-06.

Tamura, K., G. Stecher, D. Peterson, A. Filipski, and S. Kumar. 2013. MEGA6: Molecular evolutionary genetics analysis version 6.0. Mol. Biol. Evol. 30:2725-2729. https://doi.org/10.1093/molbev/ mst197.

Thomas, S. B. and R. G. Druce. 1969. Psychrotrophic bacteria in refrigerated pasteurised milk. A review. Dairy Industries 34:430-433, $501-505$.

Tompkin, R. B. 2002. Control of Listeria monocytogenes in the foodprocessing environment. J. Food Prot. 65:709-725. https://doi .org/10.4315/0362-028X-65.4.709.

Vangay, P., E. B. Fugett, Q. Sun, and M. Wiedmann. 2013. Food microbe tracker: A web-based tool for storage and comparison of food-associated microbes. J. Food Prot. 76:283-294. https://doi .org/10.4315/0362-028X.JFP-12-276.

Vongkamjan, K., S. Roof, M. J. Stasiewicz, and M. Wiedmann. 2013. Persistent Listeria monocytogenes subtypes isolated from a smoked fish processing facility included both phage susceptible and resistant isolates. Food Microbiol. 35:38-48. https://doi.org/10.1016/ j.fm.2013.02.012.

Watrous, G. H., S. E. Barnard, and W. W. Coleman. 1971. A survey of the actual and potential bacterial keeping quality of pasteurized milk from 50 Pennsylvania dairy plants. J. Milk Food Technol. 34:145-149. https://doi.org/10.4315/0022-2747-34.3.145.

Weckbach, L. S., and B. E. Langlois. 1977. Effect of heat treatments on survival and growth of a psychrotroph and on nitrogen fractions in milk. J. Food Prot. 40:857-862. https://doi.org/10.4315/0362 $-028 \mathrm{X}-40.12 .857$.

Werle, E., C. Schneider, M. Renner, M. Völker, and W. Fiehn. 1994. Convenient single-step, one tube purification of PCR products for direct sequencing. Nucleic Acids Res. 22:4354-4355.

Wessels, D., P. J. Jooste, and J. F. Mostert. 1989. Psychrotrophic, proteolytic and lipolytic properties of Enterobacteriaceae isolated from milk and dairy products. Int. J. Food Microbiol. 9:79-83. https://doi.org/10.1016/0168-1605(89)90040-8.

Wickham, H. 2016. ggplot2: Elegant Graphics for Data Analysis. 2nd ed. 2016. Springer International Publishing, Basel, Switzerland.

Wickham, H., R. Francois, L. Henry, and K. Müller. 2017. dplyr: A grammar of data manipulation. $\mathrm{R}$ package version 0.7.4. Accessed Jun. 23, 2017. https://CRAN.R-project.org/package=dplyr. 